NBER WORKING PAPER SERIES

\title{
ESTIMATING GLOBAL BANK NETWORK CONNECTEDNESS
}

\author{
Mert Demirer \\ Francis X. Diebold \\ Laura Liu \\ Kamil Y1lmaz \\ Working Paper 23140 \\ http://www.nber.org/papers/w23140
NATIONAL BUREAU OF ECONOMIC RESEARCH
1050 Massachusetts Avenue
Cambridge, MA 02138
February 2017

For helpful discussion we thank seminar participants at CORE, National Bank of Belgium, Duke University, the European University Institute, the International Monetary Fund, the PIER Policy Tools Workshop, Universite Catholique de Louvain, the University of York, Koç University, the University of Pennsylvania, the University of Minho, Bogazici University, the University of Bologna, the University of Delaware, and the Federal Reserve Bank of Richmond. We are similarly grateful to participants at the University of Chicago Conference on Machine Learning and Economics, ECB-CBRT Conference on Assessing the Macroeconomic Implications of Financial and Production Networks, the (EC)2 Annual Conference, the Econometric Society North American Winter Meetings, the Vienna Workshop on High Dimensional Time Series in Macroeconomics and Finance, and the FRB San Francisco Conference in Honor of James Hamilton. We are especially grateful to Turan Bali, Gorkem Bostanci, Christian Brownlees, Fabio Canova, Umut Gokcen, Laura Kaufmann, Serena Ng, Han Ozsoylev, Minchul Shin, David Veredas, and Tanju Yorulmazer. Demirer and Yilmaz thank the Turkish Scientific and Technological Research Council (TUBITAK) for financial support through Grant No. 111K500. The usual disclaimer applies. Demirer and Yilmaz thank the Turkish Scientific and Technological Research Council (TUBITAK) for financial support through Grant No. 111K500. The views expressed herein are those of the authors and do not necessarily reflect the views of the National Bureau of Economic Research.

NBER working papers are circulated for discussion and comment purposes. They have not been peer-reviewed or been subject to the review by the NBER Board of Directors that accompanies official NBER publications.

(C) 2017 by Mert Demirer, Francis X. Diebold, Laura Liu, and Kamil Y1lmaz. All rights reserved. Short sections of text, not to exceed two paragraphs, may be quoted without explicit permission provided that full credit, including (C) notice, is given to the source. 
Estimating Global Bank Network Connectedness

Mert Demirer, Francis X. Diebold, Laura Liu, and Kamil Y1lmaz

NBER Working Paper No. 23140

February 2017

JEL No. C01,C32,G21

\begin{abstract}
$\underline{\text { ABSTRACT }}$
We use LASSO methods to shrink, select and estimate the high-dimensional network linking the publicly-traded subset of the world's top 150 banks, 2003-2014. We characterize static network connectedness using full-sample estimation and dynamic network connectedness using rollingwindow estimation. Statically, we find that global bank equity connectedness has a strong geographic component, whereas country sovereign bond connectedness does not. Dynamically, we find that equity connectedness increases during crises, with clear peaks during the Great Financial Crisis and each wave of the subsequent European Debt Crisis, and with movements coming mostly from changes in cross-country as opposed to within-country bank linkages.
\end{abstract}

Mert Demirer

Department of Economics

Massachusetts Institute of Technology

77 Massachusetts Avenue E52-300

Cambridge, Mass. 02139

mdemirer@mit.edu

Francis X. Diebold

Department of Economics

University of Pennsylvania

3718 Locust Walk

Philadelphia, PA 19104-6297

and NBER

fdiebold@sas.upenn.edu

\section{Laura Liu}

Department of Economics

University of Pennsylvania

3718 Locust Walk

Philadelphia, PA 19104

yuliu4@sas.upenn.edu

Kamil Y1lmaz

Department of Economics

Koc University

Rumelifeneri Yolu, Sariyer

Istanbul 34450

kyilmaz@ku.edu.tr 


\section{Introduction}

Connectedness is central to modern financial risk measurement and management. It features prominently in key aspects of market risk (return connectedness and portfolio concentration), credit risk (default connectedness), counter-party and gridlock risk (bilateral and multilateral contractual connectedness), and not least, systemic risk (systemwide connectedness). It is also central to understanding underlying fundamental macroeconomic risks, in particular business cycle risk (e.g., intra- and inter-country real activity connectedness).

Recent theoretical work has therefore emphasized network connectedness in financial and industry contexts, as in Jackson (2008), Easley and Kleinberg (2010), Acemoglu et al. (2012), and Babus (2013). Related empirical work, which sometimes includes banking contexts, has begun to appear; see for example, Diebold and Yilmaz (2009), Acharya et al. (2010), Billio et al. (2012), Allen et al. (2012), Acharya et al. (2012), Barigozzi and Brownlees (2013), Diebold and Yilmaz (2014), Brownlees and Engle (2015), Bianchi et al. (2015), Giglio et al. (2016), and Adrian and Brunnermeier (2016).

There is, however, little empirical research on global bank connectedness. This is particularly unfortunate given the role of financial institutions in the Great Recession of 20072009, and given the many channels that potentially produce linkages among banks, such as counter-party relationships associated with asset/liability positions, contractual relationships associated with services provided to clients and other institutions, and correlated exposures, as well linkages via asset-price and liquidity channels. ${ }^{1}$

A key reason for the lack of empirical work on global bank connectedness is the high dimensionality of bank networks. There are simply very many important banks globally, which renders unrestricted vector-autoregressive (VAR) and related analyses intractable. Hence, for example, Diebold and Yilmaz (2014) were forced to limit their analysis to a small number of purely-U.S. institutions. Although a useful first step, such an analysis is clearly incomplete, given the global nature of the financial services industry.

In this paper we progress on both the methodological and substantive fronts. On the methodological side, we confront the dimensionality problem while nevertheless remaining squarely in the Diebold-Yilmaz connectedness measurement tradition, which is intimately related to the key summary of network structure, the degree distribution, and the key measure of network centrality, the mean degree. We do so by estimating the network using LASSO methods, which facilitates high dimensionality by selecting and shrinking in optimal ways.

\footnotetext{
${ }^{1}$ See, among others, the classic work of Shleifer and Vishny (1992), Allen and Gale (1994), Allen and Gale (2000), Cifuentes and Shin (2005), Acharya and Yorulmazer (2007), and Gorton (2015).
} 
We also maintain our intentionally reduced-form approach: Our goal is to provide a credible framework for "getting the facts straight", regardless of the underlying structural mechanism(s), particularly given the many mechanisms that may be operative, per the discussion above.

On the substantive side, no longer constrained by the dimensionality problem, we perform a truly global bank connectedness analysis. In particular, we characterize the static and dynamic high-frequency stock-return volatility connectedness of all publicly-traded banks among the world's top 150, 2004-2014.

We proceed as follows. In section 2, we briefly summarize the Diebold-Yilmaz connectednessmeasurement framework. In section 3, we introduce "LASSOed" large VAR's as empirical approximating models in the Diebold-Yilmaz framework. In sections 4 and 5, respectively, we provide static and dynamic characterizations of the global bank network, and we conclude in section 6 .

\section{Population Network Connectedness}

Here we discuss our connectedness framework and measures, in population. (We discuss estimation later, in section 3.) The discussion is brief, as we use connectedness measures based on variance decompositions, as proposed and developed in a series of earlier papers that includes Diebold and Yilmaz (2009), Diebold and Yilmaz (2012), and Diebold and Yilmaz (2014).

\subsection{Variance Decompositions for Connectedness Measurement}

Connectedness measures based on variance decompositions are appealing for several reasons. First, they make obvious intuitive sense, answering a key question, which at the most granular pairwise level is "How much of entity $i$ 's future uncertainty (at horizon $H$ ) is due to shocks arising not with entity $i$, but rather with entity $j$ ?"

Second, they allow for different connectedness at different horizons, facilitating examination of a variety of horizons and selection of a preferred horizon if desired. This is important because, for example, 1-day connectedness may be very different from 10- or 30-day connectedness.

Finally, they are closely linked to modern network theory, in particular the degree distribution and mean degree, and they are also closely linked to recently-proposed measures 
of various types of systemic risk, such as marginal expected shortfall (Acharya et al. (2010)) and CoVaR (Adrian and Brunnermeier (2016)). ${ }^{2}$

\subsection{Vector Autoregressive Approximating Models}

We base our variance decomposition on an $N$-variable $\operatorname{VAR}(p), x_{t}=\sum_{i=1}^{p} \Phi_{i} x_{t-i}+\varepsilon_{t}$, where $\varepsilon_{t} \sim(0, \Sigma)$. The moving average representation is $x_{t}=\sum_{i=0}^{\infty} A_{i} \varepsilon_{t-i}$, where the $N \mathrm{x} N$ coefficient matrices $A_{i}$ obey the recursion $A_{i}=\Phi_{1} A_{i-1}+\Phi_{2} A_{i-2}+\ldots+\Phi_{p} A_{i-p}$, with $A_{0}$ an $N \mathrm{x} N$ identity matrix and $A_{i}=0$ for $i<0$.

The high-dimensional situations that will concern us require mechanical identification schemes, but standard approaches such as Cholesky factorization depend on the ordering of the variables, which raises significant complications. Hence we follow Diebold and Yilmaz (2012) in using the "generalized identification" framework of Koop et al. (1996) and Pesaran and Shin (1998), which produces variance decompositions invariant to ordering. Instead of attempting to orthogonalize shocks, the generalized approach allows for correlated shocks but accounts appropriately for the correlation.

\subsection{Connectedness Measures}

We now introduce our connectedness measures. We proceed from highly-granular (pairwise) through highly-aggregative (systemwide).

\subsubsection{Pairwise Directional Connectedness}

Firm $j$ 's contribution to firm $i$ 's $H$-step-ahead generalized forecast error variance, $\theta_{i j}^{g}(H)$, is

$$
\theta_{i j}^{g}(H)=\frac{\sigma_{j j}^{-1} \sum_{h=0}^{H-1}\left(e_{i}^{\prime} A_{h} \Sigma e_{j}\right)^{2}}{\sum_{h=0}^{H-1}\left(e_{i}^{\prime} A_{h} \Sigma A_{h}^{\prime} e_{i}\right)}, \quad H=1,2, \ldots,
$$

where $\Sigma$ is the covariance matrix of the disturbance vector $\varepsilon, \sigma_{j j}$ is the standard deviation of the disturbance of the $j^{\text {th }}$ equation, and $e_{i}$ is the selection vector with one as the $i^{\text {th }}$ element and zeros otherwise.

Because we work in the Koop-Pesaran-Potter-Shin generalized VAR framework, the variance shares do not necessarily add to 1 ; that is, in general $\sum_{j=1}^{N} \theta_{i j}^{g}(H) \neq 1$. Hence we normalize each entry of the generalized variance decomposition matrix (1) by the row sum:

\footnotetext{
${ }^{2}$ See Diebold and Yilmaz (2014) for a detailed discussion.
} 


$$
\tilde{\theta}_{i j}^{g}(H)=\frac{\theta_{i j}^{g}(H)}{\sum_{j=1}^{N} \theta_{i j}^{g}(H)} .
$$

Now by construction $\sum_{j=1}^{N} \tilde{\theta}_{i j}^{g}(H)=1$ and $\sum_{i, j=1}^{N} \tilde{\theta}_{i j}^{g}(H)=N$.

As a matter of notation, we now convert from $\tilde{\theta}_{i j}^{g}(H)$ to $C_{i \leftarrow j}^{H}(C$ is of course for connectedness), which is less cumbersome and more directly informative.

\subsubsection{Total Directional Connectedness, "To" and "From"}

Now we get less granular, moving from pairwise directional connectedness to total directional connectedness. Total directional connectedness to firm $i$ from all other firms $j$ is:

$$
C_{i \leftarrow \bullet}^{H}=\frac{\sum_{\substack{j=1 \\ j \neq i}}^{N} \tilde{\theta}_{i j}^{g}(H)}{\sum_{i, j=1}^{N} \tilde{\theta}_{i j}^{g}(H)}=\frac{\sum_{\substack{j=1 \\ j \neq i}}^{N} \tilde{\theta}_{i j}^{g}(H)}{N} .
$$

Similarly, total directional connectedness from firm $i$ to all other firms $j$ is

$$
C_{\bullet \leftarrow i}^{H}=\frac{\sum_{\substack{j=1 \\ j \neq i}}^{N} \tilde{\theta}_{j i}^{g}(H)}{\sum_{i, j=1}^{N} \tilde{\theta}_{j i}^{g}(H)}=\frac{\sum_{\substack{j=1 \\ j \neq i}}^{N} \tilde{\theta}_{j i}^{g}(H)}{N} .
$$

\subsubsection{Systemwide Connectedness}

Now we get still less granular, proceeding to a systemwide level. Using the normalized entries of the generalized variance decomposition matrix (2), we measure total directional connectedness as

$$
C^{H}=\frac{\sum_{\substack{i, j=1 \\ i \neq j}}^{N} \tilde{\theta}_{i j}^{g}(H)}{\sum_{i, j=1}^{N} \tilde{\theta}_{i j}^{g}(H)}=\frac{\sum_{\substack{i, j=1 \\ i \neq j}}^{N} \tilde{\theta}_{i j}^{g}(H)}{N} .
$$

We call this total connectedness systemwide connectedness. It is simply the sum of total directional connectedness whether "to" or "from." (It doesn't matter which way, because "exports" must equal "imports" at the "global" level.)

\section{Sample Bank Network Connectedness}

Thus far we have discussed population network connectedness measurement. Now we discuss sample connectedness measurement, specialized, moreover, to the context of global banking, which we study in detail in sections 4 and 5 . In section 3.1 we introduce our banks, sample 
period, and object of study (realized range-based stock return volatility). In section 3.2 we discuss LASSO estimation of the high-dimensional VAR approximating model. In section 3.3 we discuss our approach to network visualization of variance decomposition matrices.

\subsection{Banks, Sample Period, and Stock Return Volatilities}

We study 96 banks from 29 developed and emerging economies, downloaded from ThomsonReuters, from September 12, 2003 through February 7, 2014. Our 96 banks are those in the world's top 150 (by assets) that were publicly traded throughout our sample. They are largely banks from developed countries: 82 are from 23 developed economies, and the remaining 14 are from 6 emerging economies. ${ }^{3}$ They include all those designated as "globally systemically important banks" ("GSIB's", as designated by the Basel Committee on Banking Supervision), except for three Chinese banks (Agricultural Bank of China, Bank of China, and Industrial and Commercial Bank of China) and one French bank (Group BCPE), which we exclude because they were not publicly traded as of September 2003.

We focus on connectedness in the global bank stock return volatility network, which does not require high-frequency balance sheet and related information, which is unavailable in real time. Instead we need only high-frequency stock return data, which are readily available. Stock market valuations are of course imperfect - like all valuations - but equity analysts devote massive time and resources to uncovering and interpreting connectedness information as relevant for valuation.

Volatility connectedness is of direct interest in financial markets. If volatility tracks investor fear (e.g., the VIX is often touted as an "investor fear gauge"), then volatility connectedness is fear connectedness. Hence volatility connectedness is of special interest from the perspective of real-time crisis monitoring, as volatilities tend to lurch and move together only in crises, whereas returns often move closely together in both crises and upswings.

Volatility is latent and must therefore be estimated. Many approaches to volatility estimation have received attention, including $\mathrm{GARCH}$, stochastic volatility, realized volatility, and implied volatility. ${ }^{4}$ We use daily range-based realized volatility. That is, following

\footnotetext{
${ }^{3}$ See the appendices for details regarding market capitalization, bank code, and Reuters ticker, by bank assets (Appendix A) and by country (Appendix B). Our bank codes are easier to interpret than the Reuters tickers, particularly as regards identifying banks' countries, so we use them in our subsequent empirical work.

${ }^{4}$ For a survey see Andersen et al. (2013).
} 
Garman and Klass (1980), we estimate daily bank stock return volatility as

$$
\begin{aligned}
\tilde{\sigma}_{i t}^{2}= & 0.511\left(H_{i t}-L_{i t}\right)^{2}-0.019\left[\left(C_{i t}-O_{i t}\right)\left(H_{i t}+L_{i t}-2 O_{i t}\right)\right. \\
& \left.-2\left(H_{i t}-O_{i t}\right)\left(L_{i t}-O_{i t}\right)\right]-0.383\left(C_{i t}-O_{i t}\right)^{2},
\end{aligned}
$$

where $H_{i t}, L_{i t}, O_{i t}$ and $C_{i t}$ are, respectively, the logs of daily high, low, opening and closing prices for bank stock $i$ on day $t$. Range-based realized volatility is nearly as efficient as realized volatility based on high-frequency intra-day sampling, yet it requires only four readily-available inputs per day, and it is robust to certain forms of microstructure noise (Alizadeh et al. (2002)).

Finally, we note that our bank stock price data come from markets located in different time zones. Although this could potentially influence the empirical results, the use of return volatilities rather than returns, and the use of a VAR approximating model, are likely to minimize the potential impact. In particular, our use of volatility in the connectedness analysis helps to identify the origins of shocks, as volatility jumps more during crises, as does our use of a vector autoregressive approximating model, to which we now turn.

\subsection{Estimation of High-Dimensionsal VAR's}

In applications we base connectedness assessment on an estimated VAR approximating model. For compelling applications, we need the VAR to be estimable in very high dimensions, somehow recovering degrees of freedom. ${ }^{5}$ One can do so by pure shrinkage (as with traditional informative-prior Bayesian analyses, or ridge regression) or pure selection (as with traditional criteria like AIC and SIC), but blending shrinkage and selection, using variants of the LASSO, proves particularly appealing.

\subsubsection{LASSO}

To understand the LASSO, consider least-squares estimation, ${ }^{6}$

$$
\hat{\beta}=\arg \min _{\beta} \sum_{t=1}^{T}\left(y_{t}-\sum_{i} \beta_{i} x_{i t}\right)^{2},
$$

\footnotetext{
${ }^{5}$ In what follows we refer to estimators that achieve this as "regularized," and associated environments as involving "regularization."

${ }^{6}$ We present LASSO for a generic regression equation $y \rightarrow X$, to maximize notational transparency. In our subsequent equation-by-equation VAR estimation, the right-hand-side variables in each equation are of course $p$ lags of each of the $N$ variables.
} 
subject to the constraint:

$$
\sum_{i=1}^{K}\left|\beta_{i}\right|^{q} \leq c
$$

Equivalently, consider the penalized estimation problem:

$$
\hat{\beta}=\arg \min _{\beta}\left(\sum_{t=1}^{T}\left(y_{t}-\sum_{i} \beta_{i} x_{i t}\right)^{2}+\lambda \sum_{i=1}^{K}\left|\beta_{i}\right|^{q}\right) .
$$

Concave penalty functions non-differentiable at the origin produce selection, whereas smooth convex penalties (e.g., $q=2$, the ridge regression estimator) produce shrinkage. Hence penalized estimation nests and can blend selection and shrinkage. The LASSO (short for "least absolute shrinkage and selection operator"), introduced in the seminal work of Tibshirani (1996), solves the penalized regression problem with $q=1$. Hence it shrinks and selects. Moreover it requires only one minimization, and it uses the smallest $q$ for which the minimization problem is convex.

\subsubsection{Adaptive Elastic Net}

A simple extension of the LASSO, the so-called adaptive elastic net (Zou and Zhang (2009)), not only shrinks and selects, but also has the oracle property, meaning (roughly) that the selected model is consistent for the best Kullback-Liebler approximation to the true DGP. In our implementation of the adaptive elastic net, we solve

$$
\hat{\beta}_{\text {AEnet }}=\arg \min _{\beta}\left(\sum_{t=1}^{T}\left(y_{t}-\sum_{i} \beta_{i} x_{i t}\right)^{2}+\lambda \sum_{i=1}^{K} w_{i}\left(\frac{1}{2}\left|\beta_{i}\right|+\frac{1}{2} \beta_{i}^{2}\right)\right),
$$

where $w_{i}=1 /\left|\hat{\beta}_{i, O L S}\right|$ and $\lambda$ is selected equation-by-equation by 10 -fold cross validation. Note that the adaptive elastic net penalty averages the "LASSO penalty" with a "ridge penalty", and moreover that it weights the average by inverse OLS parameter estimates, thereby shrinking the "smallest" OLS-estimated coefficients most heavily toward zero. ${ }^{7}$

\subsubsection{Additional Remarks}

(a) We want to encourage sparsity in our approximating model, but we do not necessarily want to impose sparsity in the implied bank network. Our approach of shrinking and se-

\footnotetext{
${ }^{7}$ The weighting by inverse estimates is responsible for the oracle property.
} 
lecting on the approximating VAR, as opposed to shrinking and selecting on the variance decomposition network directly, achieves that goal. The approximating VAR is intentionally shrunken and made sparse by the LASSO, but the variance decomposition matrix that drives our connectedness measures is a non-linear transformation of the VAR coefficients and is therefore generally not sparse. ${ }^{8}$

(b) We regularize the estimated VAR autoregressive coefficient matrices, but presently we do not pursue regularization of the shock covariance matrix, in large part because we are not necessarily comfortable with the standard "statistical" shrinkage directions (e.g., toward zero). Instead one might want to shrink and select in other directions, such as toward equicorrelation or reduced-rank structure, but we leave covariance matrix regularization to future research.

\subsection{Network Visualization of High-Dimensional Variance Decom- positions}

The issue of how best to display results takes on great importance in high-dimensional network modeling. In our subsequent empirical work, for example, we will estimate networks with approximately 100 nodes, and presenting and examining $100 \times 100=10,000$ estimated pairwise variance decompositions would be thoroughly uninformative. Hence we characterize the estimated networks graphically using five devices: node naming convention, node size, node color, node location, and link arrow sizes (two per link, because the network is directed). Throughout, we use the open-source Gephi software (https://gephi.github.io/) for network visualization.

\section{Node Naming Convention Indicates Bank and Country}

The node naming convention is bank.country, where "bank" is our bank code and "country" is our country code. For example, JP Morgan is jpm.us. ${ }^{9}$

\section{Node Size Indicates Asset Size}

\footnotetext{
${ }^{8}$ Alternative frameworks that attempt to characterize network connectedness directly from a fitted sparse VAR(1) coefficient matrix (e.g., Bonaldi et al. (2013)) force sparse networks, by construction. Moreover, they also provide incomplete connectedness characterizations, because VAR connectedness arises not only through cross-lag linkages, but also through the disturbance covariance matrix. Network connectedness measures based on Granger-causal patterns (e.g. Billio et al. (2012)) also ignore the disturbance covariance matrix and hence are similarly incomplete.

${ }^{9}$ The other bank and country codes are similarly self-evident; see the appendices for a complete listing.
} 
We make node size a linear function of bank asset size. ${ }^{10}$ We assign the sizes of the largest and smallest nodes, and then assign the rest linearly. We emphasize assets rather than market capitalization for two reasons. First, market capitalization is subject to abrupt changes due to fluctuations in stock price. Second, cross-country differences in financial system characteristics and ownership structure of publicly traded companies have direct effects on market capitalization levels, thereby producing persistent differences in cross-country market capitalizations.

Node color Indicates Total Directional Connectedness "To Others"

The node color indicates total directional connectedness to others, ranging from 3DFA02 (bright green, the weakest), to E6DF22 (luminous vivid yellow), to CF9C5B (whiskey sour), to FC1C0D (bright red), to B81113 (dark red, the strongest). We show the color range in Figure 1.

Figure 1: Network Graph Color Spectrum

Node Location Indicates Average Pairwise Directional Connectedness ${ }^{11}$

We determine node location using the ForceAtlas2 algorithm of Jacomy et al. (2014) as implemented in Gephi. The algorithm finds a steady state in which repelling and attracting forces exactly balance, where (1) nodes repel each other, but (2) links attract the nodes they connect according to average pairwise directional connectedness "to" and "from." The steady state node locations depend on initial node locations and hence are not unique. This is largely irrelevant, however, as we are interested in relative, not absolute, node locations in equilibrium.

\section{Link Arrow Sizes Indicate Pairwise Directional Connectedness "To" and "From"}

Note that because the full set of link arrow sizes reveals the full set of pairwise directional connectednesses, from which all else can be derived, most of the additional graphical devices employed (in particular, node shading and location) are in principle redundant and therefore unnecessary. In practice, however, those additional devices prove invaluable for describing large network topologies.

\footnotetext{
${ }^{10}$ Note well that we make node size and asset size linearly related, but not directly proportional. Huge asset-size differences between the largest and smallest banks in our sample make directly-proportional representation impossible.

${ }^{11}$ Link thickness also indicates average pairwise directional connectedness.
} 


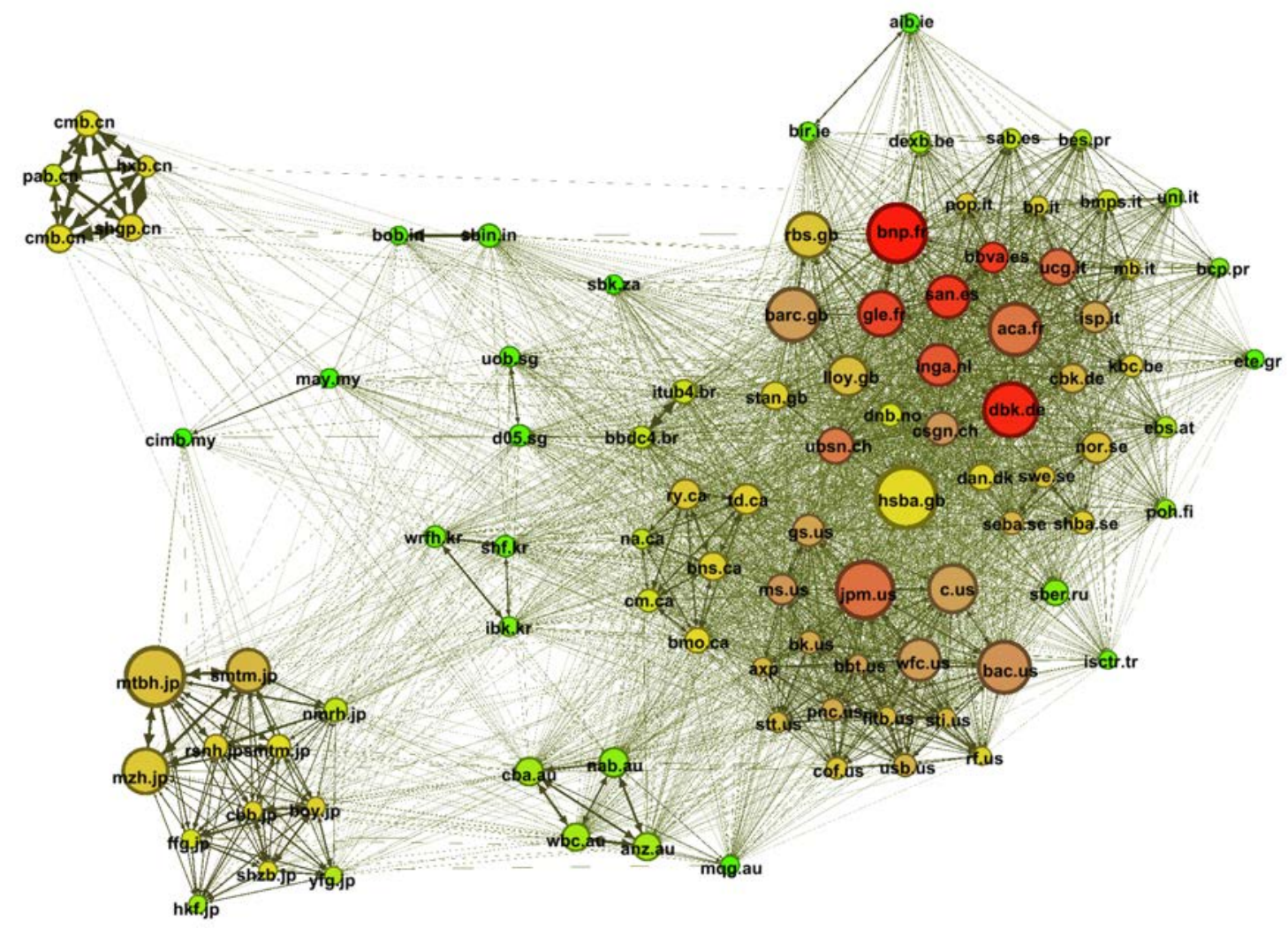

Figure 2: Individual Bank Network Graph, 2003-2014

\section{Static Estimation of the Global Bank Network}

We estimate logarithmic volatility VAR's using the adaptive elastic net as described above. Then we compute variance decompositions and corresponding connectedness measures at horizon $H=10$, using the estimated VAR parameters.

\subsection{The Individual Bank Network}

We show the full-sample global bank network graph in Figure 2. The main result is the strong clustering, both within and across countries. ${ }^{12}$ The within-country bank clustering

\footnotetext{
${ }^{12}$ A second interesting result is the high coherence between banks designated as GSIB's and those that we estimate and display as having high net total directional connectedness ("to" minus "from", $C_{\bullet \leftarrow i}^{H}-C_{i \leftarrow \bullet}^{H}$ ). When we sort banks by net connectedness, all of our top 15 banks are included in the GSIB list, as are 20 of our top 25.
} 
Table 1: Individual Bank Network Connectedness Table, Six-Group Aggregation, 2003-2014

\begin{tabular}{lrrrrrr|r}
\hline \hline & Africa & Asia & Europe & N. America & Oceania & S. America & From Others \\
\hline Africa & 0.00 & 8.51 & 18.78 & 13.84 & 1.77 & 2.14 & 45.05 \\
Asia & 4.08 & 0.00 & 205.03 & 157.42 & 30.22 & 21.90 & 418.64 \\
Europe & 6.62 & 93.44 & 0.00 & 431.31 & 20.57 & 29.31 & 581.25 \\
N. America & 3.14 & 58.72 & 417.83 & 0.00 & 20.63 & 26.91 & 527.24 \\
Oceania & 2.00 & 39.67 & 68.08 & 74.44 & 0.00 & 5.27 & 189.46 \\
S. America & 1.38 & 14.29 & 48.41 & 48.34 & 2.63 & 0.00 & 115.06 \\
\hline To Others & 17.20 & 214.65 & 758.13 & 725.35 & 75.84 & 85.53 & 312.78 \\
\hline
\end{tabular}

is ubiquitous, ranging from countries with many banks in our sample (e.g., U.S., Canada, Australia, China, Japan) to those with only two or three (e.g., Korea, Singapore, India, Malaysia). The cross-country clustering is also obvious throughout the graph, whose left side clearly tends to contain banks of eastern countries, and whose right side clearly tends to contain banks of western countries. Moreover, the western side clearly breaks into a large Anglo / European bank cluster and a smaller American / Canadian cluster, each of which contains sub-clusters.

It is not obvious that region of origin would be the dominant factor driving network connectedness. One might have thought, for example, that other factors, such as bank size, might dominate, but such is not the case. Japan illustrates this clearly. Although the majority of very large banks are located in the Anglo / American / European cluster, the three very large Japanese banks (Mitsubishi UFJ, Mizuho Financial, and Sumitomo Mitsui Financial) are located not in the Anglo / American / European cluster, but rather in the Japanese cluster.

Given the clear regional clustering in the network graph, we show in Table 1 a six-region network connectedness table. The main elements are the pairwise directional connectednesses defined in equation (2), the row sums labeled "from others" are the total directional connectednesses from others defined in equation (3), the column sums labeled "to others" are the total directional connectednesses to others defined in equation (4), and the lower right element is the systemwide connectedness defined in equation (5). The table's message is clear: North America and Europe are large (and indeed the only) net transmitters of future volatility uncertainty ("to others" - "from others") to the rest of the world. Asia also has noticeably large total directional connectedness - both large transmissions and large receipts (i.e., total directional connectedness "to" and "from") - but at this point it remains a clear net receiver. 


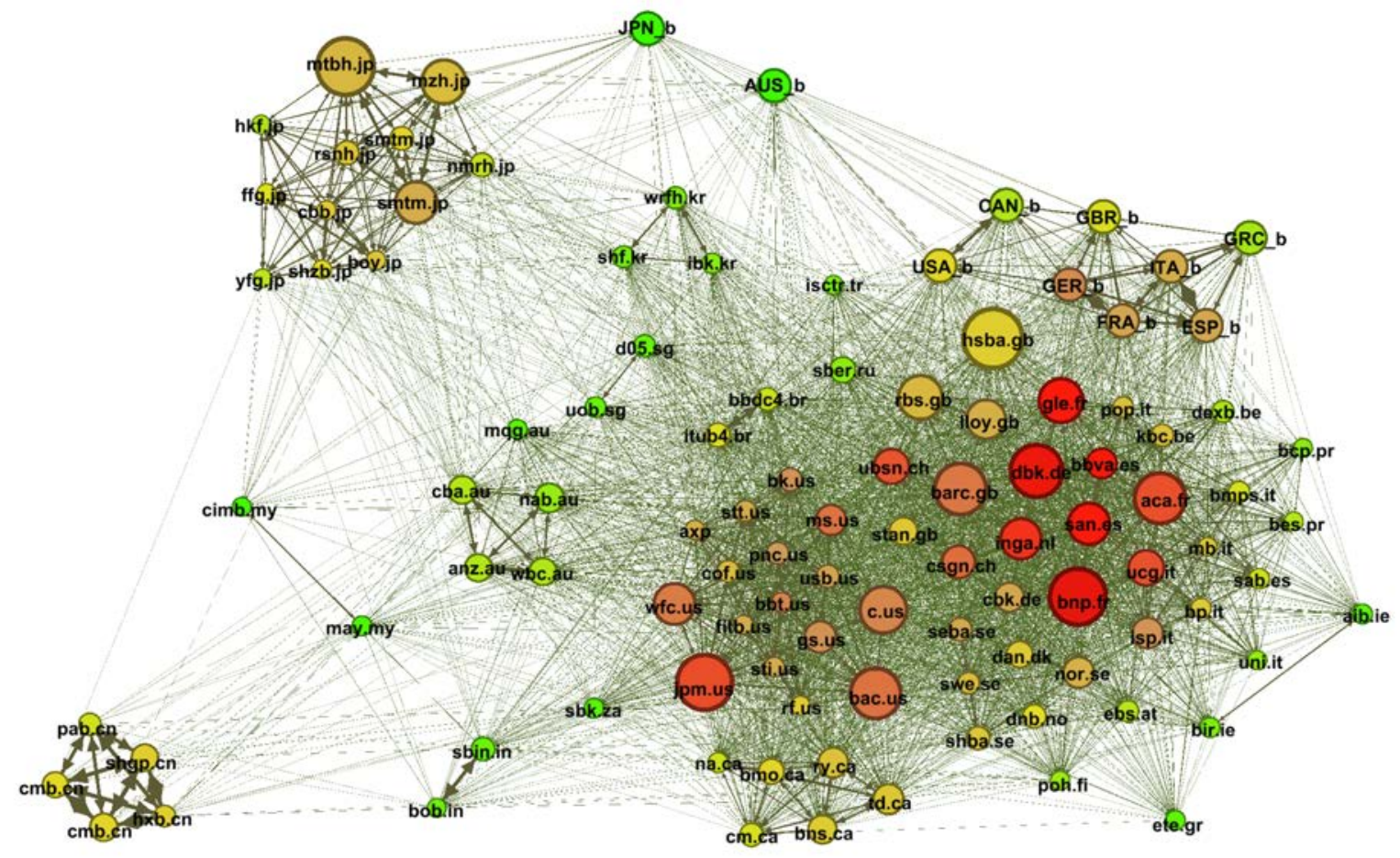

Figure 3: Individual Bank / Sovereign Bond Network, 2003-2014

\subsubsection{Including Sovereign Bonds}

Thus far we analyzed the global network of bank equity return volatilities, but we can also include other important financial asset volatilities. This is potentially interesting because, although the U.S. financial crisis did not have a sovereign debt component, the ensuing European crisis did.

Against this background, we now briefly include sovereign bond yield volatilities in the analysis, in addition to bank stock volatilities. We include 10-year G-7 sovereigns (United States, Germany, France, Japan, United Kingdom, Canada, and Italy), as well as those of Spain, Greece and Australia. We start with government bond prices, and then we convert to approximate yields using $P_{t}=1 /\left(1+r_{t}\right)^{10}$, where $P_{t}$ is price and $r_{t}$ is 10 -year yield. Then we calculate daily range-based return volatilities using the Parkinson (1980) approach, which requires only the daily highs and lows (as opposed to high, low, open, and close). That is, 
we use $\tilde{\sigma}_{i t}^{2}=0.361\left(H_{i t}-L_{i t}\right)^{2}$, where $H_{i t}$ and $L_{i t}$ are, respectively, the logs of daily high and low prices for bank stock $i$ on day $t$.

We plot the estimated individual bank / sovereign bond network in Figure 3. Several observations are in order. First, the sovereigns cluster strongly. They appear in the upper right of the graph, which is otherwise similar to Figure 2. ${ }^{13}$ Second, European bond nodes are nevertheless closer to European bank nodes, U.S. and Canadian bond nodes are closer to U.S. and Canadian bank nodes, and Japanese and Australian bond nodes are closer to Japanese and Australian bank nodes. Third, although the bond nodes are pulled toward their respective country bank nodes, they remain completely distinct and never appear inside their national/regional banking clusters: bank stocks form regional/national clusters, and sovereign bonds are not part of those clusters.

\subsection{The Country Bank Network}

In Figures 4 and 5 (without and with sovereign bonds included, respectively) we show the country bank network obtained by aggregating the earlier-discussed individual bank network. ${ }^{14}$ This serves two useful and distinct purposes.

First, examination of the country bank network is intrinsically interesting and a logical next step. Our individual-bank analysis showed strong connectedness of banks both within and across countries, so we now proceed to dig more deeply into the cross-country links. Examination of the country bank network allows us to distinguish the relative strengths of directional "to" and "from" connectedness of the most-connected country banking systems.

Second, the smaller number of links in the country bank network makes visual interpretation of connectedness simpler and more revealing. (29 countries produce only $29^{2}=841$ links in the country network, whereas 96 banks produce $96^{2}=9216$ links in the bank network.)

The equity volatility network of Figure 4 reveals that the U.S. is massively connected. The strongest U.S. links are with Canada, Great Britain, and Australia. It is not always visible, but the arrows indicate greater connectedness from the U.S. to Canada, Australia and Great Britain than conversely. The Anglo / European countries form a cluster just above the U.S. Of the Anglo / European countries, Britain has the strongest links to and from the U.S. The northern European countries are to the south-east of the cluster; Sweden has the strongest connectedness with the U.S. Ireland, Portugal, Greece, Finland and Austria are

\footnotetext{
${ }^{13}$ The country bond node naming convention is COUNTRY_b, where "COUNTRY" is our country code (capitalized) and "b" denotes bond. For example, the U.S. government bond is USA_b. The other country codes are generally similarly self-evident; see the appendices for a complete listing.

${ }^{14}$ We place country nodes at the centers of gravity of the corresponding country banks.
} 


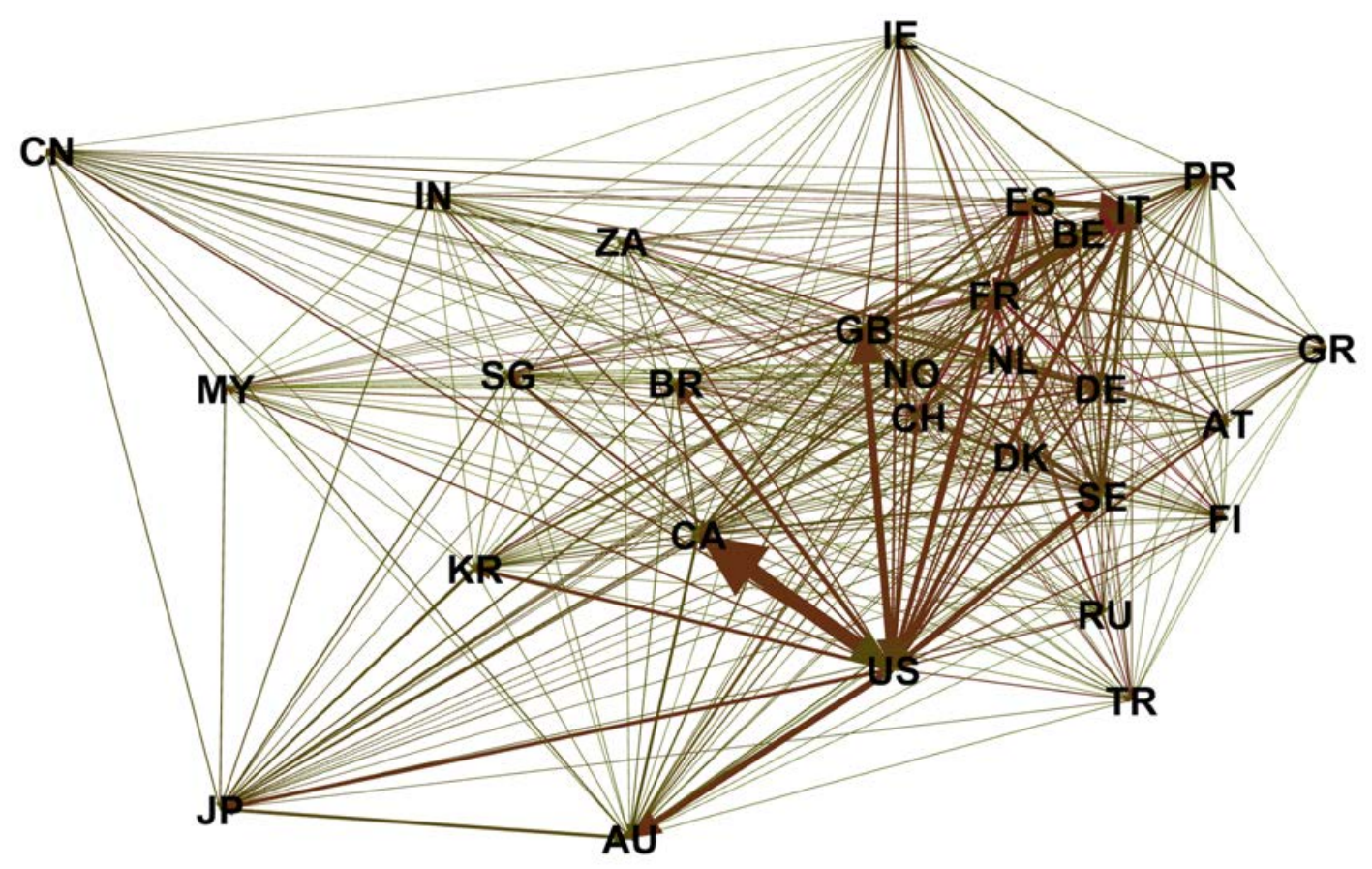

Figure 4: Country Bank Network, 2003-2014

located on the perimeter of the cluster. Other countries are scattered farther away from the European cluster. As noted previously for individual banks, moving leftward on the graph generally takes one from western to eastern countries. Finally, the equity/bond volatility network of Figure 5 reveals that, as in the individual bank analysis, the bonds cluster tightly, regardless of geography.

\section{Dynamic Estimation of the Global Bank Network}

We now characterize the global banking network dynamically. We use rolling estimation with a 150-day window, with repeated cross validation of the penalty parameter $\lambda$ in each window. ${ }^{15}$ We start with comparisons of estimated network graphs "before and after" ma-

\footnotetext{
${ }^{15}$ For rolling estimation we switch from adaptive elastic net to elastic net, meaning that we use $w_{i}=1$ rather than $w_{i}=1 /\left|\hat{\beta}_{i, O L S}\right|$ in the estimator (9), because we found that the elastic net produces less noisy
} 


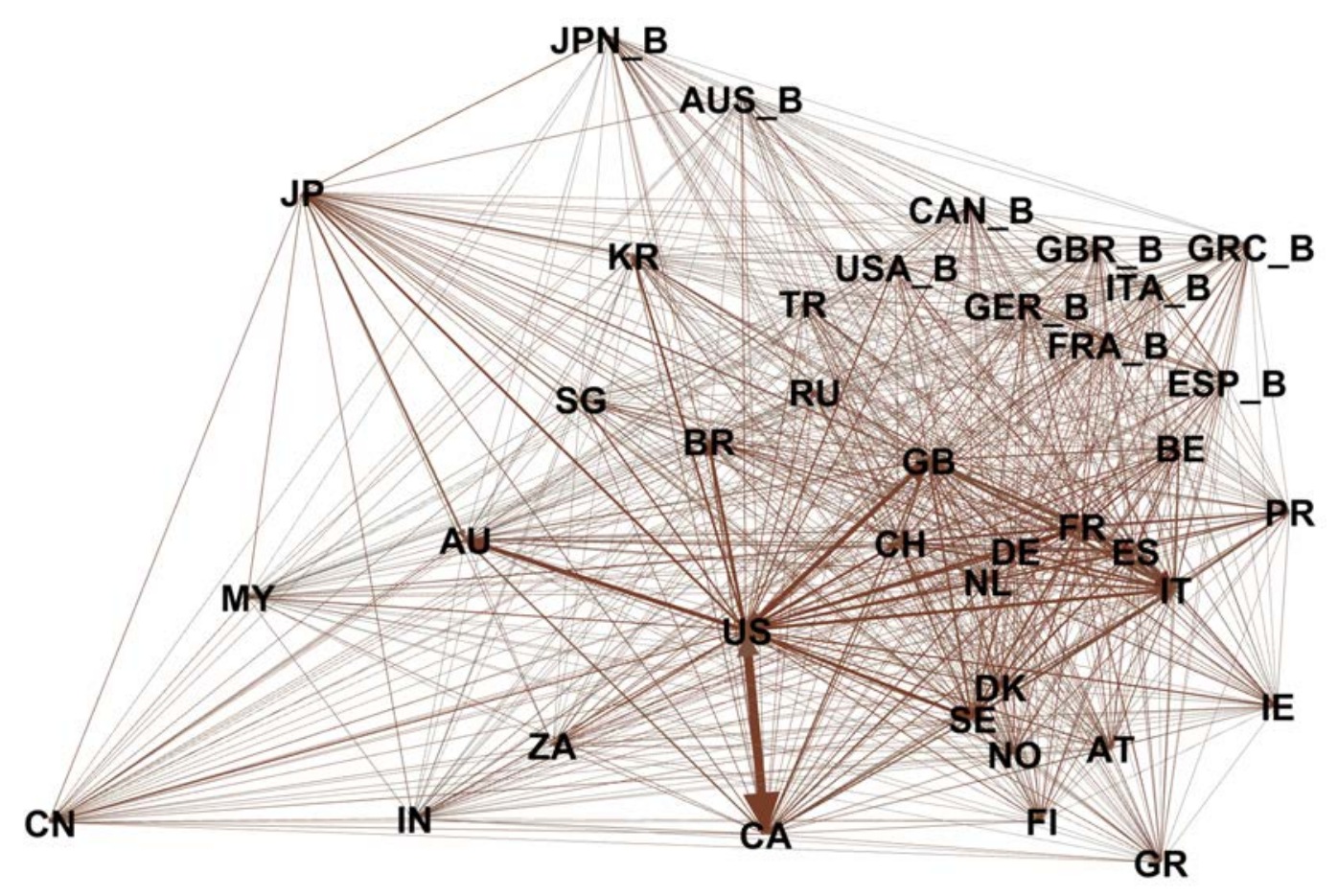

Figure 5: Country Bank / Sovereign Bond Network, 2003-2014

jor crisis episodes, and then we proceed to examine the continuous real-time evolution of systemwide connectedness.

\subsection{Banks Pre- and Post-Lehman}

The critical point in the financial crisis was Lehman's bankruptcy, which was announced on September 15, 2008. In Figure 6 we show the 96-bank network graphs on September 1, 2008 and on November 21, 2008. There is a clear difference between the individual bank network graphs on the two dates.

In particular, connectedness of U.S. banks with others increased sharply after Lehman's collapse and the transformation of the U.S. financial crisis into a global one. Before the Lehman collapse, the U.S. and European banks stood far apart around the Anglo / American estimates under rolling estimation. 


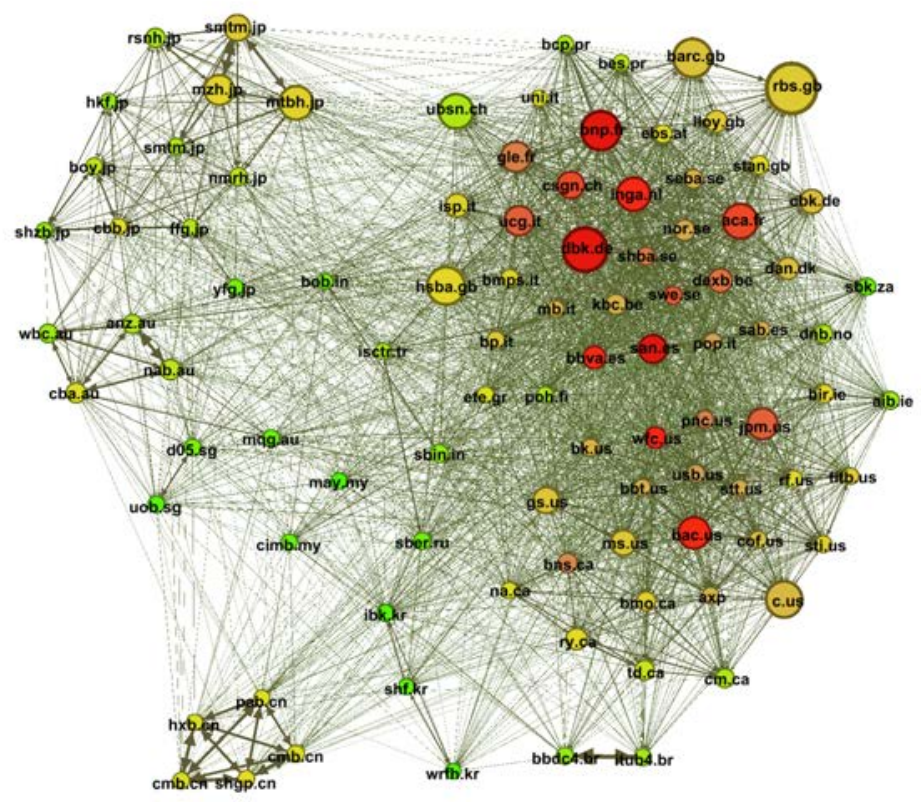

(a) September 1, 2008

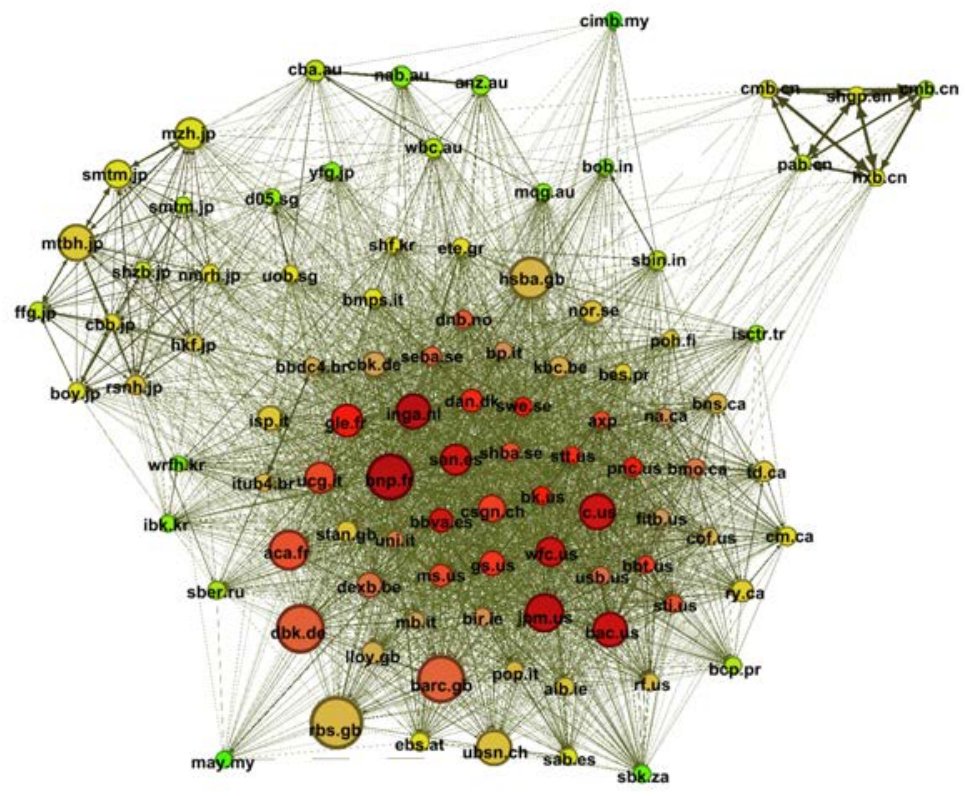

(b) November 21, 2008

Figure 6: Individual Bank Network Pre- and Post-Lehman 
/ European cluster, with a visible gap in the network graph between the U.S. and European banks. The Japanese and Chinese banks also stood apart. Once the Lehman shock hit global markets, the entire individual bank network, perhaps with the exception of Chinese banks, moved closer together, indicating the spread of volatility across bank stocks and countries. It is important to stress that volatility data coming from stock markets operating in different time zones does not prevent our framework from capturing the sharp increase in pairwise directional connectedness after the collapse of Lehman Brothers.

A similar picture arises when we analyze the country bank network before and after Lehman's collapse. We show the country bank network graphs in Figure 7. Connectedness was comparatively weak before the collapse, and much stronger afterward. Moreover, the directional volatility connectedness from the U.S. to others increased substantially.

\subsection{Banks, Bonds, and the European Debt Crisis}

To see how the individual bank / sovereign bond network was transformed following the European banking and sovereign bond crisis, we analyze the network graph once the European sovereign debt and banking crisis spread throughout the continent, affecting mostly the periphery countries such as Greece, Portugal, Ireland, Italy and Spain. However, sovereign bonds of the center countries such as Germany, France and the Great Britain could not be isolated from the events unfolding in the periphery. As a result, on October 7, 2011 connectedness reached its highest level since the global financial crisis of late $2008 .{ }^{16}$

In Figure 8(a) we show the October 2011 individual bank / sovereign bond network, and in Figure 8(b) we once again show the full-sample network for comparison. The graphs are quite different. The October 2011 bond yield volatilities are no longer on the outskirts of the regional / national banking clusters. Indeed, bond yield volatilities for the U.S., the UK, Germany and France moved toward the center of the European / North American banking cluster. Italy and Spain did not move to the center of the cluster, but they are still closer to the center of Anglo / American / European cluster than they were in the full sample. Greek bonds, on the other hand, are separated from other sovereign bonds (including the European bonds) as well as individual banks. ${ }^{17}$ Australian bonds moved closer to the Japanese bonds. Furthermore, the nodes for the Japanese and Chinese banks, as well as the ones from other countries, moved closer to the Anglo / American / European cluster, indicating stronger

\footnotetext{
${ }^{16}$ More precisely, systemwide connectedness peaked on October 7, 2011, as shown in Figure 9.

${ }^{17}$ We believe that this is a reflection of the declining exposure of the European banks to Greek sovereign bonds from EUR 189 bn in the beginning of 2010 to EUR 104 bn at the end of 2011. (Sources: BIS Quarterly Review, June 2010 and June 2012, Table 9B).
} 


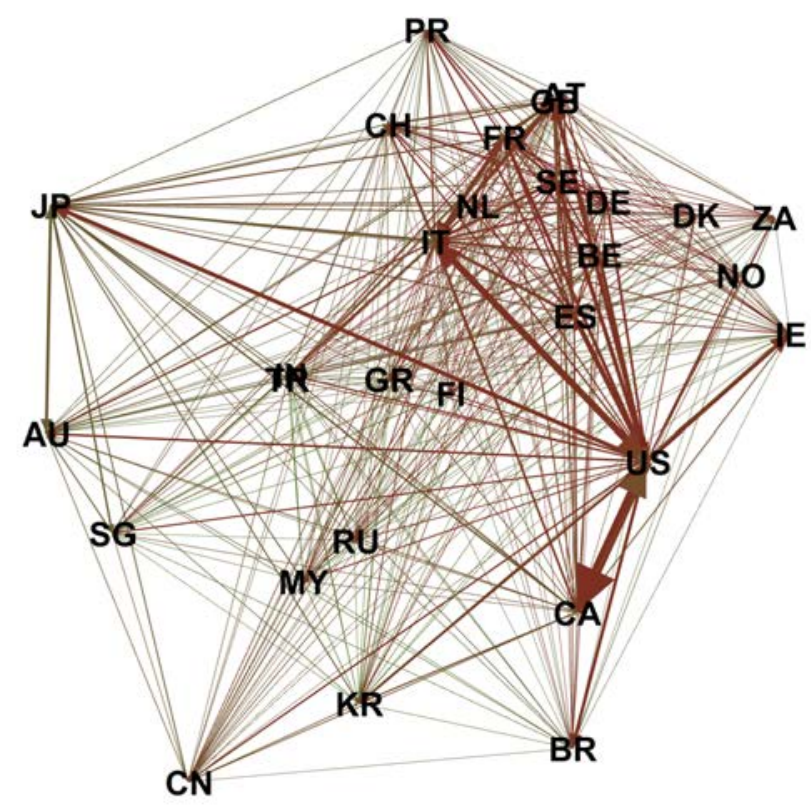

(a) September 1, 2008

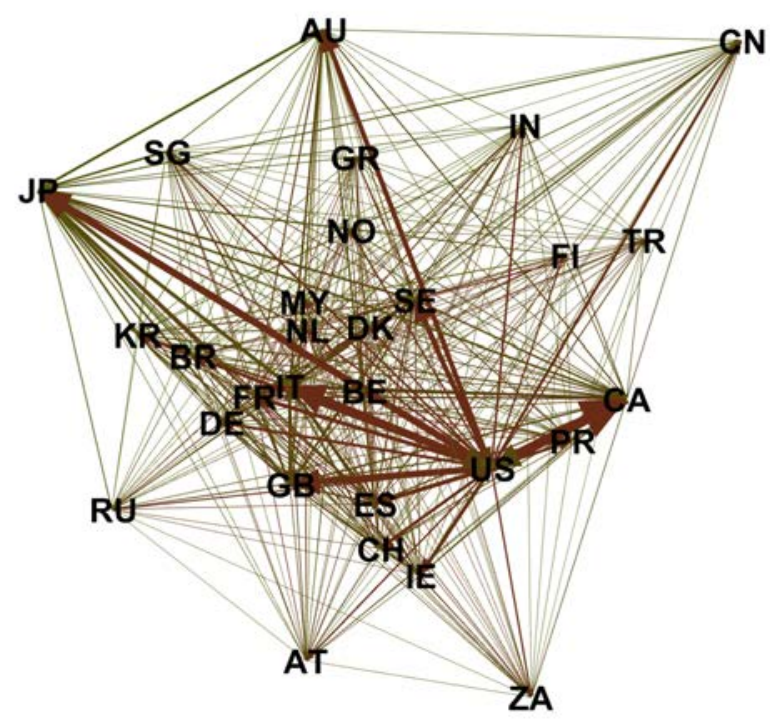

(b) November 21, 2008

Figure 7: Country Bank Network Pre- and Post-Lehman 


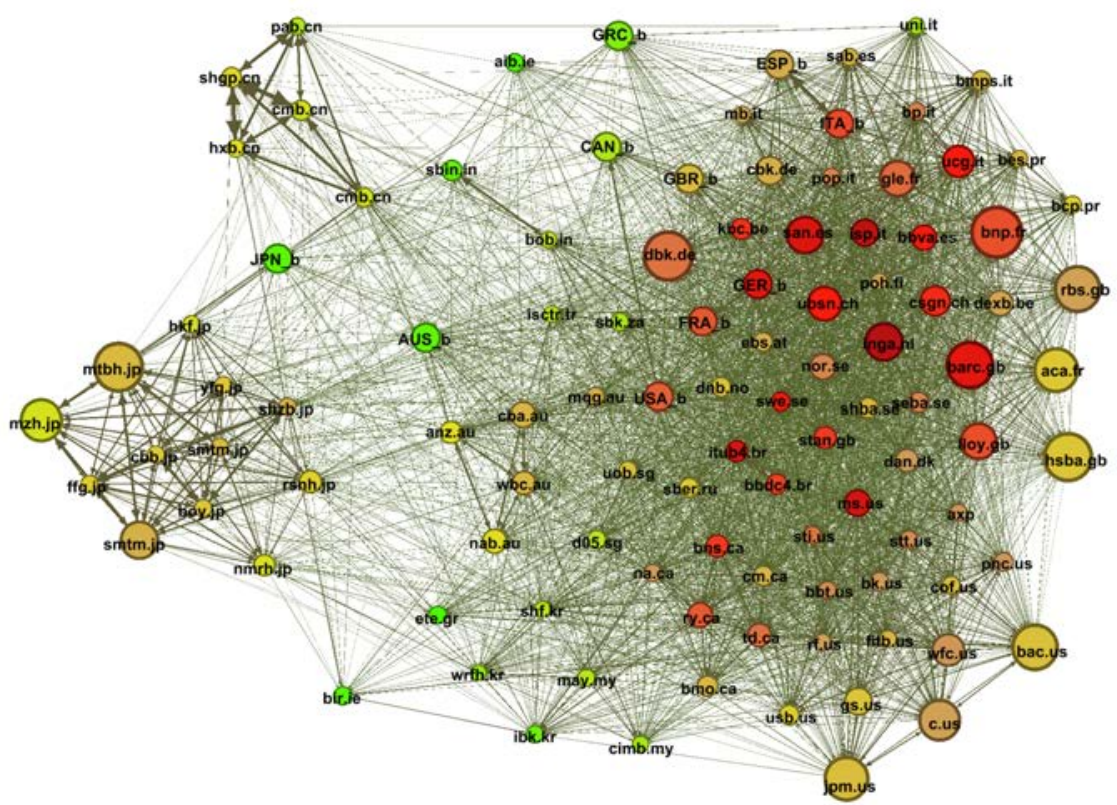

(a) Rolling Estimation, 150-Day Window Ending October 7, 2011

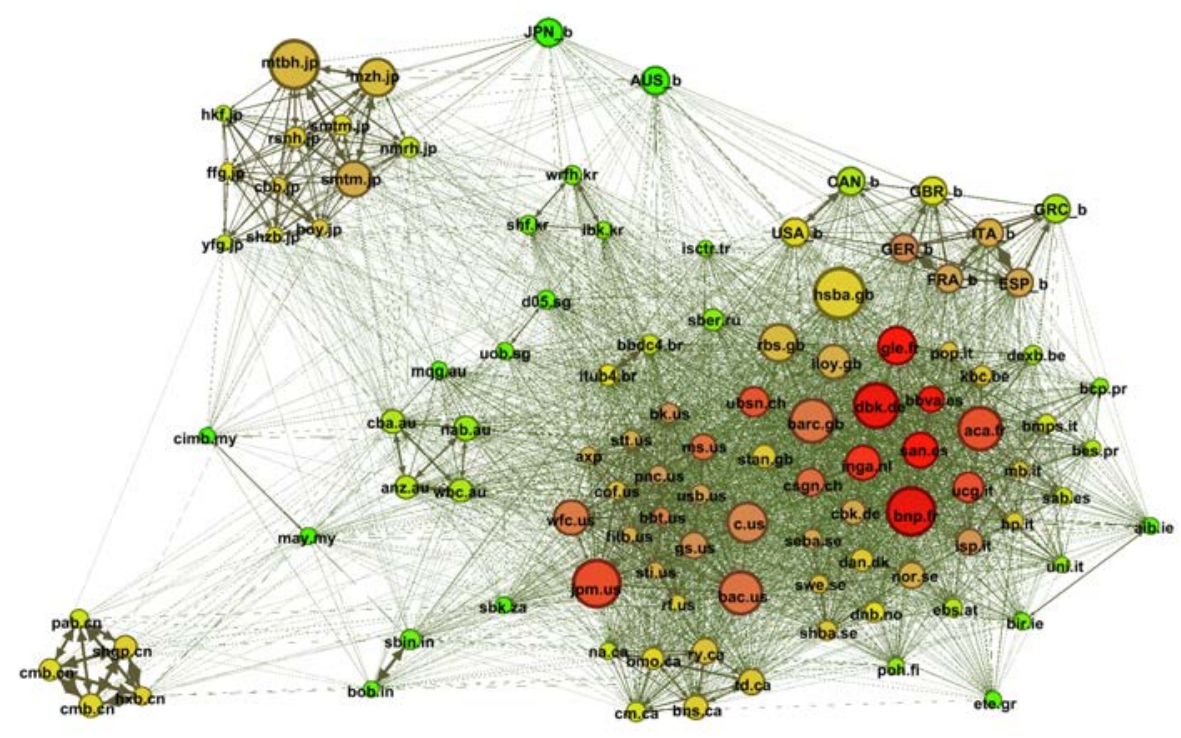

(b) Full-Sample Estimation

Figure 8: Individual Bank / Sovereign Bond Network, Full-Sample vs. After the European Crisis 
volatility connectedness in October 2011 compared to the full sample.

All told, Figure 8 clearly shows that the European banking and sovereign debt crises had become intertwined as of October 2011. The U.S. banks are farther away from the center of the Anglo / American / European cluster, and the European banks are at the center, close to the government bond markets of the U.S., France, Germany, and the U.K.

\subsection{Systemwide Connectedness}

Now we consider systemwide connectedness. There are two interesting ways to display and decompose it: trend vs. cycle and cross-country vs. within-country. We consider them in turn.

\subsubsection{Trend and Cycle}

We first display and decompose dynamic systemwide connectedness into secular (trend) and cyclical variation, as shown in Figure 9. As indicated by the superimposed piecewise linear trend, systemwide connectedness broadly increased for roughly the first half of our sample, peaking with the Lehman bankruptcy. It then decreased gradually, albeit with some major bumps associated with the two waves of the European debt crisis, falling by almost twenty percentage points relative to its peak by the end of the sample.

Let us first discuss aspects of the pre-Lehman episode. First, the connectedness of major global bank stocks increased following the Fed's unexpected decision to tighten monetary policy in May and June 2006. However, there was no other major volatility shock across the global banking system in 2006, so that estimated connectedness subsides as the observations for May-June 2006 vanish from the rolling-window. Volatility connectedness was low in early 2007. However, following the collapse of several mortgage originators in the U.S., connectedness increased sharply. This jump was followed by an even greater jump during the liquidity crisis of August 2007, when it became apparent that along with the U.S. banks the European banks also had to write off billions of dollars of losses due to their investments in mortgage backed securities. By the end of 2007, it became apparent that the major U.S. banks would end up writing of tens of billions of dollars in losses. Then in March 2008, Bear Stearns, one of the top U.S. investment banks, was acquired by J.P. Morgan to avoid bankruptcy.

Now consider the post-Lehman episode. Systemwide connectedness reached its peak following the Lehman bankruptcy on September 15, 2008, at which time the U.S. govern- 


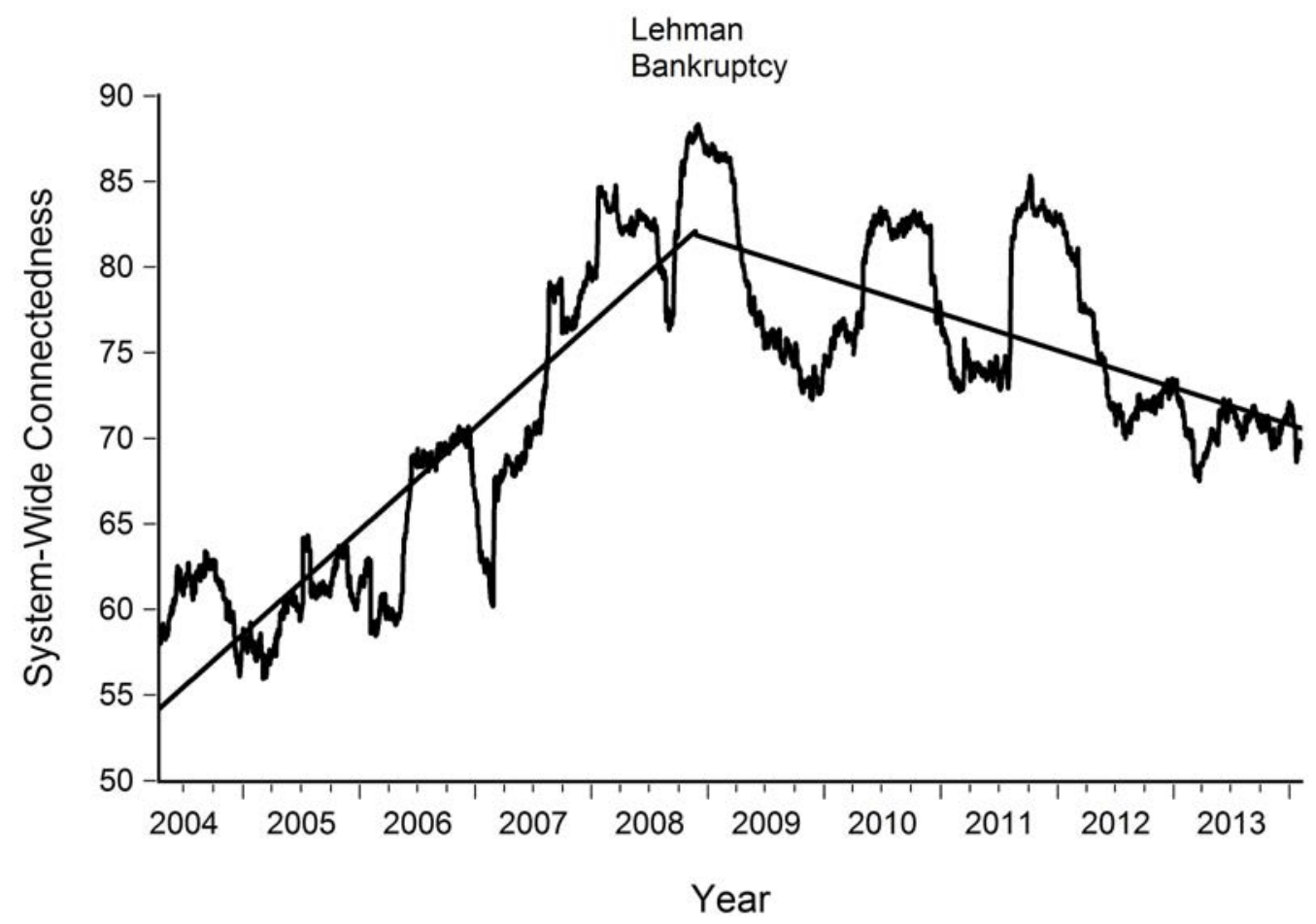

Figure 9: Systemwide Connectedness, With Superimposed Trend

ment introduced a huge package of direct capital injection in major U.S. banks. As months passed, the U.S. markets calmed, and systemwide connectedness started to trend downward. However, in 2009 and 2010 the EU member countries were shocked by developments in the banking and sovereign debt markets of some of its peripheral member countries, including Greece, Ireland and Portugal. Then in 2011, Italy and Spain joined the countries with stressed banking systems and sovereign bond markets. As a result, systemwide connectedness experienced two more significant jumps in May 2010 (due to delay in the rescue package for Greece) and in July-August 2011 (due to spread of sovereign debt and banking sector worries to Spain and Italy).

In closing this section, it may be useful to offer conjectures regarding not only aspects of the connecteness increase during the 2007-2008 crisis, but also regarding the subsequent connectedness decrease, and similarly for the various European debt crises. Connectedness could have increased more in the weeks after the Lehman collapse, had the U.S. government decided not to rescue AIG. Moreover, connectedness decreased more quickly in the months after Lehman's collapse as the U.S. government used the USD 700 bn Troubled Asset Relief 


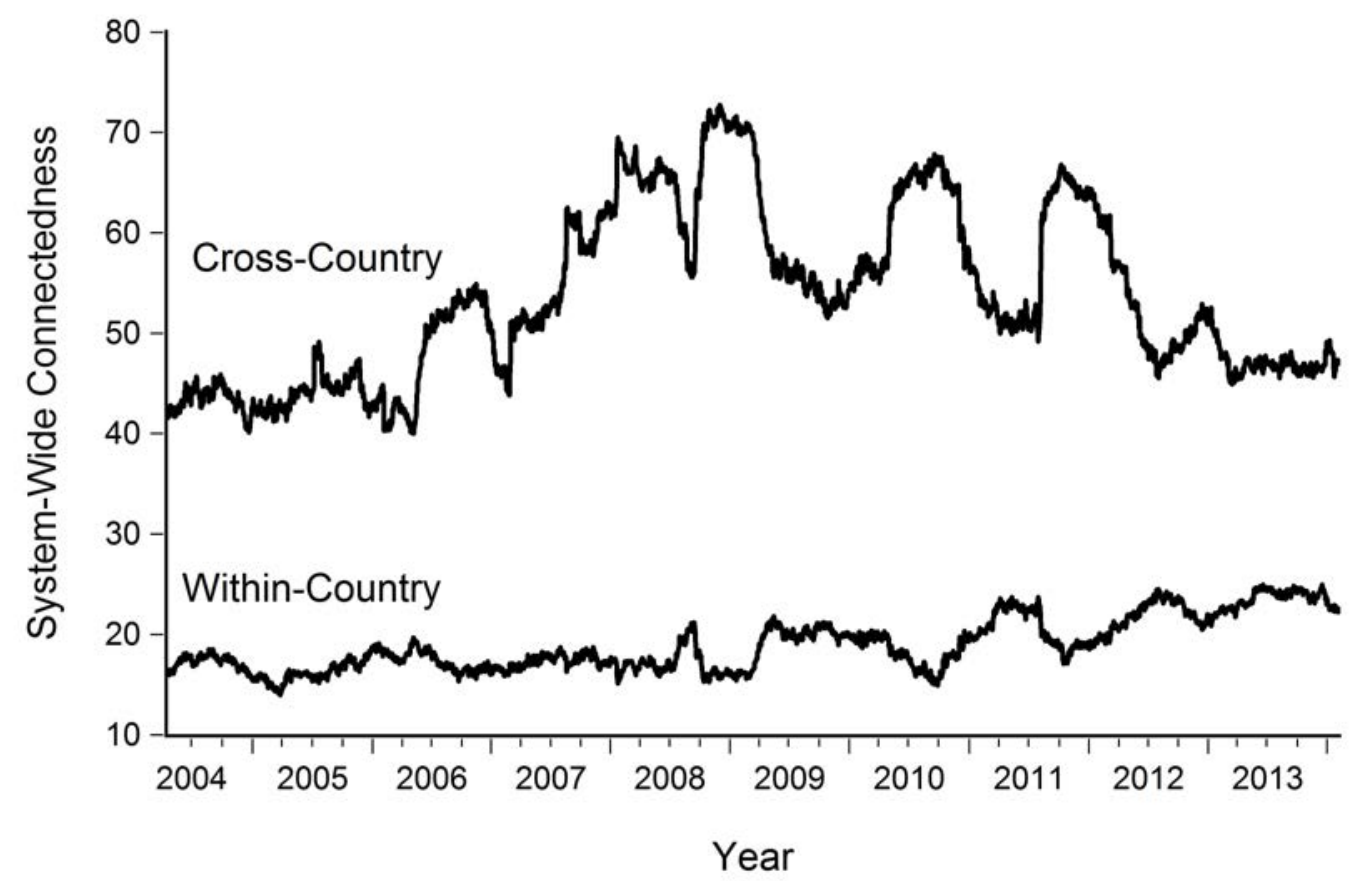

Figure 10: Systemwide Connectedness, Cross-Country and Within-Country

Program (TARP) to inject capital into the major U.S. banks. That decision helped increase confidence in the U.S. banking system and hence prevented a potential breakdown of the global financial system. Finally, stress test results also indicated that U.S. banks were sound and led to a significant decline in systemwide connectedness in 2009. As for subsequent crises, in the Greek debt crisis of 2009-2010, the ECB/IMF/EC rescue package proved effective, and in the European banking and sovereign debt crisis of 2011, the intervention of ECB under the new president Mario Draghi eventually brought down systemwide connectedness, as the ECB announced a three-year EUR 1 tr Long-term Refinancing Operation (LTRO) package that provided liquidity to many of the banks that had difficulty in borrowing in the overnight market.

\subsubsection{Cross-Country and Within-Country}

A second way to display and decompose dynamic systemwide connectedness involves crosscountry and within-country parts, as in Figure 10. Cross-country systemwide connectedness is the sum of all pairwise connectedness across banks located in different countries. Withincountry systemwide connectedness is the sum of pairwise connectedness across banks in the 
same country. By construction cross-country and within-country systemwide connectedness must sum to systemwide connectedness. The decomposition is of interest because exploring the country origins of volatility shocks and their temporal evolution may help us better understand the dynamics of global bank connectedness.

The decomposition shows that most movements in systemwide connectedness are due to movements in cross-country systemwide connectedness. Cross-country systemwide connectedness is around 40\% from 2004 to May 2006, but it then begins to fluctuate significantly. Following the Fed's unexpected decision to further tighten U.S. monetary policy, cross-country systemwide connectedness increases by around 15\% in May-December 2006. Following this episode, cross-country connectedness continues to vary throughout the sample.

It is interesting to note the decline in within-country connectedness in 2008 Q4. ${ }^{18} \mathrm{We}$ conjecture that there are at least two reasons. First, U.S. intervention following the Lehman collapse likely increased confidence in the U.S. financial system and reduced within-U.S. connectedness in 2008 Q4. As there are sixteen U.S. banks in our analysis, the decline in within-U.S. connectedness induces a decline in the overall within-country connectedness. The second reason follows from the simple aritmhmetic of connectedness. Systemwide connectedness is equal to the sum of cross-country and within-country connectedness. Once the U.S. financial crisis was transformed into a global one in the last quarter of 2008, cross-country connectedness increased sharply, with U.S. banks spreading shocks to European banks. At that point the systemwide connectedness was already $88 \%$, and we know that it bounded above by 100. As it approaches 100 it takes smaller steps. Therefore, as the cross-country connectedness increases sharply, the within-country connectedness becomes less important and hence declines. A similar dynamic appears in 2010 and 2011 during the European sovereign debt and banking crises.

\subsection{Size and Eigenvalue Centrality}

One of the primary goals of network analysis is evaluating the relative importance of individual network members. This is highly relevant for our global banking network, because, as shown during the recent global financial crisis, an individual bank may be the source of financial stress that can be transmitted to the whole system. Furthermore, from a policy viewpoint, detecting such systemically important financial institutions carries enormous importance in preventing future crises.

In Diebold and Yilmaz (2014) and thus far in this paper, we emphasized total directional

\footnotetext{
${ }^{18}$ We thank a referee for pointing this out.
} 

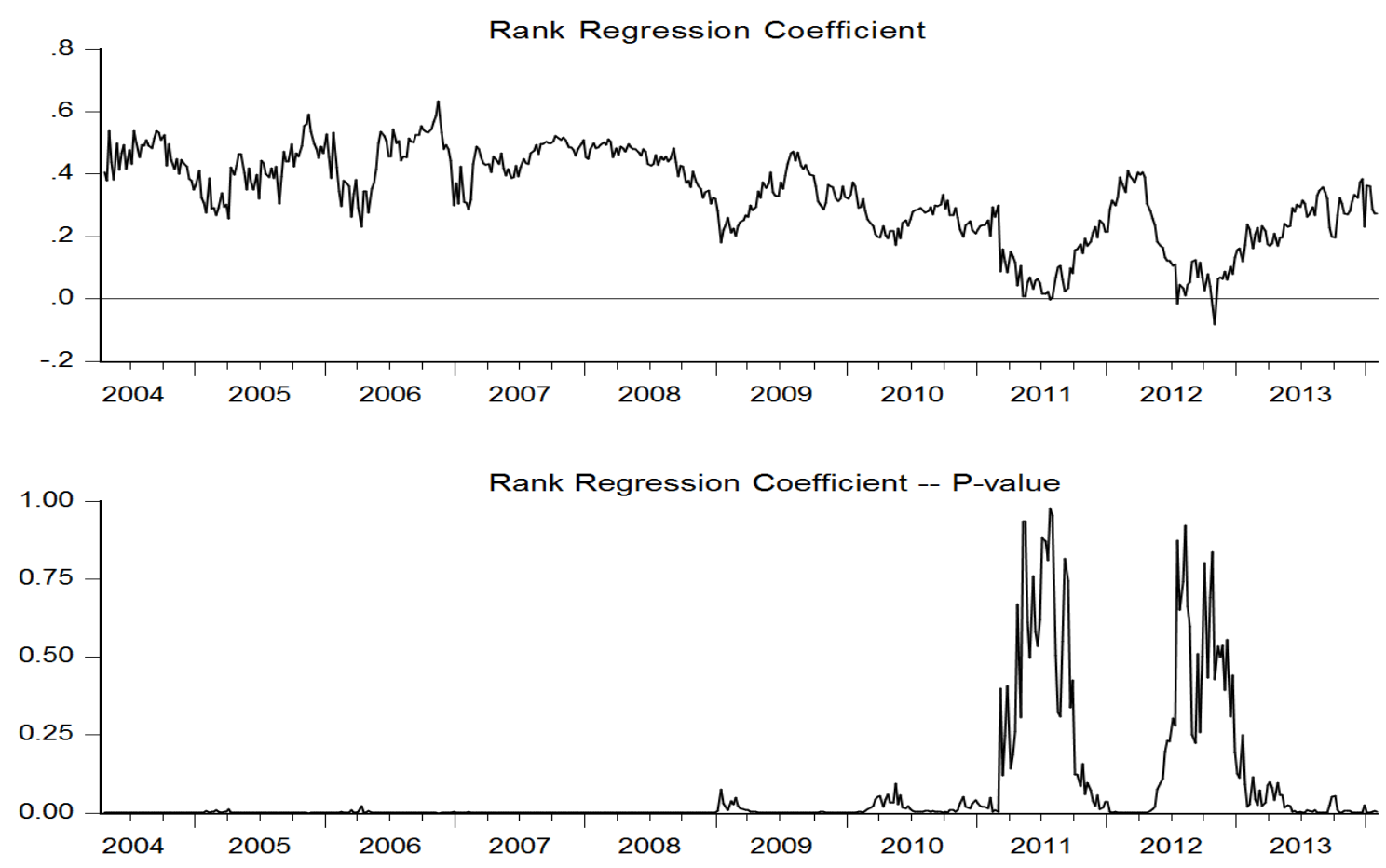

Figure 11: Rank Regression of Eigenvalue Centrality on Market Capitalization

connectedness to others for ranking systemically important institutions. ${ }^{19}$ But that captures only 1-step links, whereas there may be multi-step links as well. ${ }^{20}$ To explore this, we calculate the eigenvalue centrality $S_{t}$, which incorporates connectedness at all numbers of steps, for each bank in our sample. $S_{t}$ satisfies

$$
S_{t}=C_{t} S_{t}
$$

where $S_{t}$ is the Nx1 vector of bank eigenvector centralities and $C_{t}$ is the NxN network connectedness (adjacency) matrix. The solution for $S_{t}$ in equation (10) corresponds to eigenvector associated with the largest eigenvalue of $C_{t}$. More intuitively, note that equation (10) makes clear that the eigenvalue centrality for a given bank is equal to the sum of the centralities of the connected banks weighted by the sizes of the respective links.

From our earlier-estimated time series of $C_{t}$, we can calculate the corresponding series

\footnotetext{
${ }^{19}$ In Diebold and Yilmaz (2014) we also noted the close relationship between CoVaR (Adrian and Brunnermeier (2016))and total directional connectedness to others.

${ }^{20}$ For example, banks A and C may not be directly (1-step) linked, but A may be linked to B, and B to $\mathrm{C}$, so that $\mathrm{A}$ and $\mathrm{C}$ are indirectly linked (in this eample, 2-step linked).
} 
of estimated $S_{t}$, which then allows us to investigate the dynamic interaction between bank market capitalization and centrality. Toward that objective, we estimate the cross-section rank regression of bank centrality on market capitalization for each sub-sample window. ${ }^{21}$ Figure 11 presents the rank regression coefficient and its p-value over the rolling windows. In line with expectations, bank eigenvalue centrality is highly correlated with bank size, with the regression coefficient fluctuating between 0.4 and 0.6 in 2004 and 2005. More importantly, however, the relationship between centrality rank and size rank weakens during the global financial crisis of 2008-2009. It even disappears completely during the second phase of the European debt crisis in summer 2011 and late 2012, when the coefficient p-value moves well above the $5 \%$ level.

On the basis of this evidence we can conclude that, whereas the largest banks are more likely to be central in the global financial system in good times, smaller banks can also become central during bad times and generate volatility connectedness that will have systemic implications.

So far in this section we focused on the relationship between banks' market capitalization and eigenvalue centrality in the volatility network. Alternatively, we can focus on the relationship between banks' GSIB status and eigenvalue centrality. Towards that end, we regress the eigenvalue centrality rank of banks on a constant term along with a dummy that indicates whether the bank is included in the GSIB list at the beginning of that year. Figure 12 reports the evolution of the estimated coefficient and its p-value. The negative coefficient estimate on the GSIB dummy indicates that GSIB's are likely to be more central (higher eigenvalue centrality measure) than non-GSIB's. Except for a short time in the pre-crisis period (2004-2006), the central position of GSIB's in the network tends to be statistically significant. An average of -26 for the coefficient estimate from mid-2006 onward indicates that, everything else equal, a GSIB is likely to be ranked 25 banks ahead of a non-GSIB when ranked according to the eigenvalue centrality measure.

\section{Conclusion}

We have used LASSO methods to shrink, select and estimate the high-dimensional network linking the publicly-traded subset of the world's top 150 banks, 2003-2014. We characterized static network connectedness using full-sample estimation and dynamic network connected-

\footnotetext{
${ }^{21}$ The series we use in our rank regression analysis is measured at weekly frequency, rather than the daily frequency used throughout the rest of the paper. For conversion we use end-of-week centralities and capitalizations.
} 

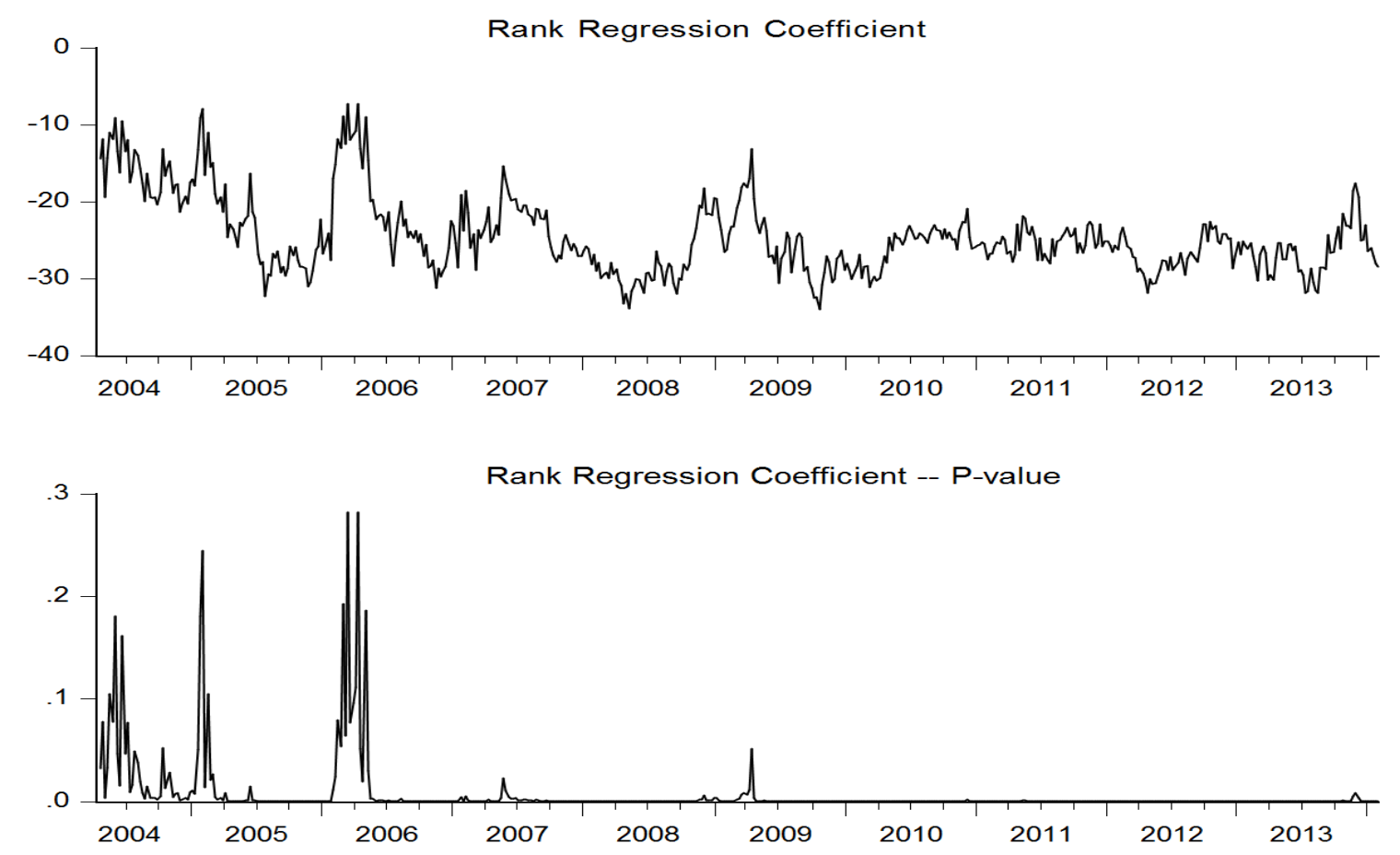

Figure 12: Regression of Eigenvalue Centrality Rank on GSIB Dummy

ness using rolling-window estimation. Statically, we found that global bank equity connectedness has a strong geographic component, whereas country sovereign bond connectedness does not. Dynamically, we found that equity connectedness increases during crises, with clear peaks during the Great Financial Crisis and each wave of the subsequent European Debt Crisis, and with movements coming mostly from changes in cross-country as opposed to within-country bank linkages.

\section{Appendices}

\section{A Global Bank Detail, by Assets}

Here we provide detail on our sample of all 96 publicly-traded banks in the world's top 150 (by assets). In Table 2 we show the banks ordered by assets, and we provide market 
capitalizations and assets (both in billions of U.S. dollars), our bank codes (which shows country), and Reuters tickers. The bank codes are easier to understand than the Reuters ticker, particularly as regards identifying banks' countries, so we use them in our empirical work.

Table 2: Global Bank Detail (Ordered by Assets)

\begin{tabular}{|c|c|c|c|c|c|}
\hline $\begin{array}{l}\text { Bank } \\
\text { Name }\end{array}$ & $\overline{\text { Country }}$ & Mcap & Asset & $\begin{array}{l}\text { Bank } \\
\text { Code }\end{array}$ & $\begin{array}{c}\text { Reuters } \\
\text { Ticker }\end{array}$ \\
\hline HSBC Holdings & UK & 2010 & 2.671 & hsba.gb & hsba.ln \\
\hline Mitsubishi UFJ Financial Group & Japan & 822 & 2.504 & mtbh.jp & X8306.to \\
\hline BNP Paribas & France & 1000 & 2.482 & bnp.fr & bnp.fr \\
\hline JPMorgan Chase \& Co & US & 2180 & 2.416 & jpm.us & jpm \\
\hline Deutsche Bank & Germany & 498 & 2.224 & dbk.de & dbk.xe \\
\hline Barclays & UK & 682 & 2.174 & barc.gb & barc.ln \\
\hline Credit Agricole & France & 367 & 2.119 & aca.fr & aca.fr \\
\hline Bank of America & US & 1770 & 2.102 & bac.us & bac \\
\hline Citigroup & US & 1500 & 1.880 & c.us & $\mathrm{c}$ \\
\hline Mizuho Financial Group & Japan & 497 & 1.706 & mzh.jp & 8411.to \\
\hline Societe Generale & France & 516 & 1.703 & gle.fr & gle.fr \\
\hline Royal Bank of Scotland Group & UK & 356 & 1.703 & rbs.gb & rbs.ln \\
\hline Sumitomo Mitsui Financial Group & Japan & 643 & 1.567 & smtm.jp & 8316.to \\
\hline Banco Santander & Spain & 1030 & 1.538 & san.es & san.mc \\
\hline Wells Fargo & US & 2430 & 1.527 & wfc.us & wfc \\
\hline ING Groep & Netherland & 557 & 1.490 & inga.nl & inga.ae \\
\hline Lloyds Banking Group & UK & 961 & 1.403 & lloy.gb & lloy.ln \\
\hline Unicredit & Italy & 477 & 1.166 & ucg.it & ucg.mi \\
\hline UBS & Switzerland & 802 & 1.138 & ubsn.ch & ubsn.vx \\
\hline Credit Suisse Group & Switzerland & 503 & 983 & csgn.ch & csgn.vx \\
\hline Goldman Sachs Group & US & 742 & 912 & gs.us & gs \\
\hline Nordea Bank & Sweden & 556 & 870 & nor.se & ndasek.sk \\
\hline Intesa Sanpaolo & Italy & 458 & 864 & isp.it & isp.mi \\
\hline Morgan Stanley & US & 577 & 833 & ms.us & $\mathrm{ms}$ \\
\hline Toronto-Dominion Bank & Canada & 827 & 827 & td.ca & td.t \\
\hline Royal Bank of Canada & Canada & 935 & 825 & ry.ca & ry.t \\
\hline Banco Bilbao Vizcaya Argentaria & Spain & 708 & 803 & bbva.es & bbva.mc \\
\hline Commerzbank & Germany & 206 & 759 & cbk.de & cbk.xe \\
\hline National Australia Bank & Australia & 724 & 755 & nab.au & nab.au \\
\hline Bank of Nova Scotia & Canada & 698 & 713 & bns.ca & bns.t \\
\hline Commonwealth Bank of Australia & Australia & 1100 & 688 & cba.au & cba.au \\
\hline Standard Chartered & UK & 524 & 674 & stan.gb & stan.ln \\
\hline China Merchants Bank & China & 358 & 664 & cmb.cn & 600036.sh \\
\hline Australia and New Zealand Banking Group & Australia & 776 & 656 & anz.au & anz.au \\
\hline Westpac Banking & Australia & 918 & 650 & wbc.au & wbc.au \\
\hline Shanghai Pudong Development Bank & China & 295 & 608 & shgp.cn & $600000 . \mathrm{sh}$ \\
\hline Danske Bank & Denmark & 256 & 597 & dan.dk & danske.ko \\
\hline Sberbank Rossii & Russia & 594 & 552 & sber.ru & sber.mz \\
\hline
\end{tabular}


Table 2 - Continued from previous page

\begin{tabular}{|c|c|c|c|c|c|}
\hline $\begin{array}{l}\text { Bank } \\
\text { Name }\end{array}$ & Country & Mcap & Asset & $\begin{array}{l}\text { Bank } \\
\text { Code }\end{array}$ & $\begin{array}{c}\text { Reuters } \\
\text { Ticker }\end{array}$ \\
\hline China Minsheng Banking Corp & China & 297 & 533 & cmb.cn & 600016.sh \\
\hline Bank of Montreal & Canada & 419 & 515 & bmo.ca & bmo.t \\
\hline Itau Unibanco Holding & Brazil & 332 & 435 & itub4.br & itub4.br \\
\hline Resona Holdings & Japan & 122 & 434 & rsnh.jp & 8308.to \\
\hline Nomura Holdings & Japan & 256 & 422 & nmrh.jp & 8604.to \\
\hline Sumitomo Mitsui Trust Holdings & Japan & 184 & 406 & smtm.jp & 8309.to \\
\hline State Bank of India & India & 165 & 400 & sbin.in & sbin.in \\
\hline DNB ASA & Norway & 289 & 396 & dnb.no & dnb.os \\
\hline Svenska Handelsbanken & Sweden & 309 & 388 & shba.se & shba.sk \\
\hline Skandinaviska Enskilda Banken & Sweden & 291 & 387 & seba.se & seba.sk \\
\hline Canadian Bank of Commerce & Canada & 324 & 382 & cm.ca & cm.t \\
\hline Bank of New York Mellon & US & 363 & 374 & bk.us & bk.us \\
\hline U.S. Bancorp & US & 745 & 364 & usb.us & usb \\
\hline Banco Bradesco & Brazil & 235 & 355 & bbdc4.br & bbdc4.br \\
\hline KBC Groupe & Belgium & 260 & 333 & kbc.be & kbc.bt \\
\hline PNC Financial Services Group & US & 435 & 320 & pnc.us & pnc.us \\
\hline DBS Group Holdings & Singapore & 320 & 318 & d05.sg & d05.sg \\
\hline Ping An Bank & China & 190 & 313 & pab.cn & $000001 . s z$ \\
\hline Woori Finance Holdings & Korea & 84 & 309 & wrfh.kr & 053000.se \\
\hline Dexia & Belgium & 1 & 307 & dexb.be & dexb.bt \\
\hline Capital One Financial & US & 415 & 297 & cof.us & cof \\
\hline Shinhan Financial Group & Korea & 188 & 295 & shf.kr & 055550.se \\
\hline Swedbank & Sweden & 308 & 284 & swe.se & sweda.sk \\
\hline Hua Xia Bank & China & 124 & 276 & hxb.cn & 600015.sh \\
\hline Erste Group Bank & Austria & 168 & 276 & ebs.at & ebs.vi \\
\hline Banca Monte dei Paschi di Siena & Italy & 29 & 275 & bmps.it & bmps.mi \\
\hline State Street Corporation & US & 30 & 243 & stt.us & stt.us \\
\hline Banco de Sabadell & Spain & 131 & 225 & sab.es & sab.mc \\
\hline United Overseas Bank & Singapore & 251 & 225 & uob.sg & u11.sg \\
\hline Banco Popular Espanol & Spain & 13 & 204 & pop.es & pop.mc \\
\hline Industrial Bank of Korea & Korea & 66 & 193 & ibk.kr & 024110.se \\
\hline BB\&T Corp & US & 266 & 183 & bbt.us & bbt \\
\hline Bank of Ireland & Ireland & 146 & 182 & bir.ie & bir.db \\
\hline National Bank of Canada & Canada & 131 & 180 & na.ca & na.t \\
\hline SunTrust Banks & US & 203 & 175 & sti.us & sti.us \\
\hline Banco Popolare & Italy & 36 & 174 & bp.it & bp.mi \\
\hline Malayan Banking Berhad & Malaysia & 263 & 171 & may.my & maybank.ku \\
\hline Allied Irish Banks & Ireland & 999 & 162 & aib.ie & aib.db \\
\hline Standard Bank Group & South Africa & 177 & 161 & sbk.za & sbk.jo \\
\hline American Express & US & 947 & 153 & $\operatorname{axp}$ & $\operatorname{axp}$ \\
\hline National Bank of Greece & Greece & 121 & 153 & ete.gr & ete.at \\
\hline Macquarie Group & Australia & 160 & 143 & mqg.au & mqg.au \\
\hline Fukuoka Financial Group & Japan & 33 & 137 & ffg.jp & 8354.to \\
\hline Bank Of Yokohama & Japan & 63 & 134 & boy.jp & 8332.to \\
\hline Pohjola Bank & Finland & 58 & 132 & poh.fi & poh1s.he \\
\hline Fifth Third Bancorp & US & 185 & 130 & fitb.us & fitb.us \\
\hline Regions Financial & US & 143 & 117 & rf.us & rf.us \\
\hline
\end{tabular}


Table 2 - Continued from previous page

\begin{tabular}{|c|c|c|c|c|c|}
\hline $\begin{array}{l}\text { Bank } \\
\text { Name }\end{array}$ & Country & Mcap & Asset & $\begin{array}{l}\text { Bank } \\
\text { Code }\end{array}$ & $\begin{array}{c}\text { Reuters } \\
\text { Ticker }\end{array}$ \\
\hline Chiba Bank & Japan & 52 & 117 & cbb.jp & 8331.to \\
\hline Unipol Gruppo Finanziario & Italy & 28 & 116 & uni.it & uni.mi \\
\hline Banco Comercial Portugues & Portugal & 51 & 113 & bcp.pr & bcp.lb \\
\hline CIMB Group Holdings & Malaysia & 163 & 113 & cimb.my & cimb.ku \\
\hline Bank of Baroda & India & 37 & 113 & bob.in & bankbaroda.in \\
\hline Turkiye Is Bankasi & Turkey & 89 & 112 & isctr.tr & isctr.is \\
\hline Banco Espirito Santo & Portugal & 71 & 111 & bes.pr & bes.lb \\
\hline Hokuhoku Financial Group & Japan & 25 & 108 & hkf.jp & 8377.to \\
\hline Shizuoka Bank & Japan & 61 & 104 & shzb.jp & 8355.to \\
\hline Mediobanca Banca di Credito Finanziario & Italy & 85 & 95 & mb.it & mb.mi \\
\hline Yamaguchi Financial Group & Japan & 23 & 93 & yfg.jp & 8418.to \\
\hline
\end{tabular}

\section{B Global Bank Detail, by Country}

In Table 3 we show the same banks by country, starting with those countries with the most banks, and proceeding through those countries with fewer banks.

Table 3: Global Bank Detail (Ordered by Country)

\begin{tabular}{|c|c|c|c|c|c|}
\hline $\begin{array}{l}\text { Bank } \\
\text { Name }\end{array}$ & Country & Mcap & $\overline{\text { Asset }}$ & $\begin{array}{l}\text { Bank } \\
\text { Code }\end{array}$ & $\begin{array}{c}\text { Reuters } \\
\text { Ticker }\end{array}$ \\
\hline JPMorgan Chase \& Co & US & 2180 & 2.416 & jpm.us & jpm \\
\hline Bank of America & US & 1770 & 2.102 & bac.us & bac \\
\hline Citigroup & US & 1500 & 1.880 & c.us & $\mathrm{c}$ \\
\hline Wells Fargo & US & 2430 & 1.527 & wfc.us & wfc \\
\hline Goldman Sachs Group & US & 742 & 912 & gs.us & gs \\
\hline Morgan Stanley & US & 577 & 833 & ms.us & $\mathrm{ms}$ \\
\hline Bank of New York Mellon & US & 363 & 374 & bk.us & bk.us \\
\hline U.S. Bancorp & US & 745 & 364 & usb.us & usb \\
\hline PNC Financial Services Group & US & 435 & 320 & pnc.us & pnc.us \\
\hline Capital One Financial & US & 415 & 297 & cof.us & cof \\
\hline State Street Corporation & US & 30 & 243 & stt.us & stt.us \\
\hline BB\&T Corp & US & 266 & 183 & bbt.us & BBT \\
\hline SunTrust Banks & US & 203 & 175 & sti.us & sti.us \\
\hline American Express & US & 947 & 153 & $\operatorname{axp}$ & $\operatorname{axp}$ \\
\hline Fifth Third Bancorp & US & 185 & 130 & fitb.us & fitb.us \\
\hline Regions Financial & US & 143 & 117 & rf.us & rf.us \\
\hline Mitsubishi UFJ Financial Group & Japan & 822 & 2.504 & mtbh.jp & X8306.to \\
\hline Mizuho Financial Group & Japan & 497 & 1.706 & mzh.jp & 8411.to \\
\hline Sumitomo Mitsui Financial Group & Japan & 643 & 1.567 & smtm.jp & 8316.to \\
\hline Resona Holdings & Japan & 122 & 434 & rsnh.jp & 8308.to \\
\hline
\end{tabular}

Continued on next page 
Table 3 - Continued from previous page

\begin{tabular}{|c|c|c|c|c|c|}
\hline $\begin{array}{l}\text { Bank } \\
\text { Name }\end{array}$ & Country & Mcap & Asset & $\begin{array}{l}\text { Bank } \\
\text { Code }\end{array}$ & $\begin{array}{c}\text { Reuters } \\
\text { Ticker }\end{array}$ \\
\hline Nomura Holdings & Japan & 256 & 422 & nmrh.jp & 8604.to \\
\hline Sumitomo Mitsui Trust Holdings & Japan & 184 & 406 & smtm.jp & 8309.to \\
\hline Fukuoka Financial Group & Japan & 33 & 137 & ffg.jp & 8354.to \\
\hline Bank Of Yokohama & Japan & 63 & 134 & boy.jp & 8332.to \\
\hline Chiba Bank & Japan & 52 & 117 & cbb.jp & 8331.to \\
\hline Hokuhoku Financial Group & Japan & 25 & 108 & hkf.jp & 8377.to \\
\hline Shizuoka Bank & Japan & 61 & 104 & shzb.jp & 8355.to \\
\hline Yamaguchi Financial Group & Japan & 23 & 93 & yfg.jp & 8418.to \\
\hline Toronto-Dominion Bank & Canada & 827 & 827 & td.ca & td.t \\
\hline Royal Bank of Canada & Canada & 935 & 825 & ry.ca & ry.t \\
\hline Bank of Nova Scotia & Canada & 698 & 713 & bns.ca & bns.t \\
\hline Bank of Montreal & Canada & 419 & 515 & bmo.ca & bmo.t \\
\hline Canadian Bank of Commerce & Canada & 324 & 382 & cm.ca & cm.t \\
\hline National Bank of Canada & Canada & 131 & 180 & na.ca & na.t \\
\hline Unicredit & Italy & 477 & 1.166 & ucg.it & ucg.mi \\
\hline Intesa Sanpaolo & Italy & 458 & 864 & isp.it & isp.mi \\
\hline Banca Monte dei Paschi di Siena & Italy & 29 & 275 & bmps.it & bmps.mi \\
\hline Banco Popolare & Italy & 36 & 174 & bp.it & bp.mi \\
\hline Unipol Gruppo Finanziario & Italy & 28 & 116 & uni.it & uni.mi \\
\hline Mediobanca Banca di Credito Finanziario & Italy & 85 & 95 & mb.it & mb.mi \\
\hline National Australia Bank & Australia & 724 & 755 & nab.au & nab.au \\
\hline Commonwealth Bank of Australia & Australia & 1100 & 688 & cba.au & cba.au \\
\hline Australia and New Zealand Banking Group & Australia & 776 & 656 & anz.au & anz.au \\
\hline Westpac Banking & Australia & 918 & 650 & wbc.au & wbc.au \\
\hline Macquarie Group & Australia & 160 & 143 & mqg.au & mqg.au \\
\hline China Merchants Bank & China & 358 & 664 & cmb.cn & $600036 . \mathrm{sh}$ \\
\hline Shanghai Pudong Development Bank & China & 295 & 608 & shgp.cn & 600000.sh \\
\hline China Minsheng Banking Corp & China & 297 & 533 & cmb.cn & 600016.sh \\
\hline Ping An Bank & China & 190 & 313 & pab.cn & 000001.sz \\
\hline Hua Xia Bank & China & 124 & 276 & hxb.cn & 600015.sh \\
\hline HSBC Holdings & UK & 2010 & 2.671 & hsba.gb & hsba.ln \\
\hline Barclays & UK & 682 & 2.174 & barc.gb & barc.ln \\
\hline Royal Bank of Scotland Group & UK & 356 & 1.703 & rbs.gb & rbs.ln \\
\hline Lloyds Banking Group & UK & 961 & 1.403 & lloy.gb & lloy.ln \\
\hline Standard Chartered & UK & 524 & 674 & stan.gb & stan.ln \\
\hline Banco Santander & Spain & 1030 & 1.538 & san.es & san.mc \\
\hline Banco Bilbao Vizcaya Argentaria & Spain & 708 & 803 & bbva.es & bbva.mc \\
\hline Banco de Sabadell & Spain & 131 & 225 & sab.es & sab.mc \\
\hline Banco Popular Espanol & Spain & 13 & 204 & pop.es & pop.mc \\
\hline Nordea Bank & Sweden & 556 & 870 & nor.se & ndasek.sk \\
\hline Svenska Handelsbanken & Sweden & 309 & 388 & shba.se & shba.sk \\
\hline Skandinaviska Enskilda Banken & Sweden & 291 & 387 & seba.se & seba.sk \\
\hline Swedbank & Sweden & 308 & 284 & swe.se & sweda.sk \\
\hline BNP Paribas & France & 1000 & 2.482 & bnp.fr & bnp.fr \\
\hline Credit Agricole & France & 367 & 2.119 & aca.fr & aca.fr \\
\hline Societe Generale & France & 516 & 1.703 & gle.fr & gle.fr \\
\hline Woori Finance Holdings & Korea & 84 & 309 & wrfh.kr & 053000.se \\
\hline
\end{tabular}


Table 3 - Continued from previous page

\begin{tabular}{lccccc}
\hline Bank & Country & Mcap & Asset & $\begin{array}{c}\text { Bank } \\
\text { Code }\end{array}$ & $\begin{array}{c}\text { Reuters } \\
\text { Ticker }\end{array}$ \\
\hline Shinhan Financial Group & Korea & 188 & 295 & shf.kr & $055550 . s e$ \\
Industrial Bank of Korea & Korea & 66 & 193 & ibk.kr & 024110.se \\
\hline UBS & Switzerland & 802 & 1.138 & ubsn.ch & ubsn.vx \\
Credit Suisse Group & Switzerland & 503 & 983 & csgn.ch & csgn.vx \\
\hline KBC Groupe & Belgium & 260 & 333 & kbc.be & kbc.bt \\
Dexia & Belgium & 1 & 307 & dexb.be & dexb.bt \\
\hline Itau Unibanco Holding & Brazil & 332 & 435 & itub4.br & itub4.br \\
Banco Bradesco & Brazil & 235 & 355 & bbdc4.br & bbdc4.br \\
\hline Deutsche Bank & Germany & 498 & 2.224 & dbk.de & dbk.xe \\
Commerzbank & Germany & 206 & 759 & cbk.de & cbk.xe \\
\hline Bank of Ireland & Ireland & 146 & 182 & bir.ie & bir.db \\
Allied Irish Banks & Ireland & 999 & 162 & aib.ie & aib.db \\
\hline State Bank of India & India & 165 & 400 & sbin.in & sbin.in \\
Bank of Baroda & India & 37 & 113 & bob.in & bankbaroda.in \\
\hline Malayan Banking Berhad & Malaysia & 263 & 171 & may.my & maybank.ku \\
CIMB Group Holdings & Malaysia & 163 & 113 & cimb.my & cimb.ku \\
\hline Banco Comercial Portugues & Portugal & 51 & 113 & bcp.pr & bcp.lb \\
Banco Espirito Santo & Portugal & 71 & 111 & bes.pr & bes.lb \\
\hline DBS Group Holdings & Singapore & 320 & 318 & d05.sg & d05.sg \\
United Overseas Bank & Singapore & 251 & 225 & uob.sg & u11.sg \\
\hline Erste Group Bank & Austria & 168 & 276 & ebs.at & ebs.vi \\
\hline Danske Bank & Denmark & 256 & 597 & dan.dk & danske.ko \\
\hline Pohjola Bank & Finland & 58 & 132 & poh.fi & poh1s.he \\
\hline National Bank of Greece & Greece & 121 & 153 & ete.gr & ete.at \\
\hline ING Groep & Netherlands & 557 & 1.490 & inga.nl & inga.ae \\
\hline DNB ASA & Norway & 289 & 396 & dnb.no & dnb.os \\
\hline Sberbank Rossii & Russia & 594 & 552 & sber.ru & sber.mz \\
\hline Turkiye Is Bankasi & Turkey & 89 & 112 & isctr.tr & isctr.is \\
\hline Standard Bank Group & South Africa & 177 & 161 & sbk.za & sbk.jo \\
\hline \hline
\end{tabular}

\section{References}

Acemoglu, D., V.M. Carvalho, A. Ozdaglar, and A. Tahbaz-Salehi (2012), "The Network Origins of Aggregate Fluctuations," Econometrica, 80, 1977-2016.

Acharya, V. and T. Yorulmazer (2007), "Too Many to Fail: An Analysis of Timeinconsistency in Bank Closure Policies," Journal of Financial Intermediation, 16, 1-31.

Acharya, V.V., R.F. Engle, and M. Richardson (2012), "Capital Shortfall: A New Approach to Ranking and Regulating Systemic Risks," American Economic Review, 102, 59-64.

Acharya, V.V., L. Pedersen, T. Philippon, and M. Richardson (2010), "Measuring Systemic Risk," Manuscript, New York University. 
Adrian, T. and M. Brunnermeier (2016), "CoVaR," American Economic Review, 106, 17051741.

Alizadeh, S., M.W. Brandt, and F.X. Diebold (2002), "Range-Based Estimation of Stochastic Volatility Models," Journal of Finance, 57, 1047-1091.

Allen, F. and D. Gale (1994), "Limited Market Participation and the Volatility of Asset Prices," American Economic Review, 84, 933-955.

Allen, F. and D. Gale (2000), "Financial Contagion," Journal of Political Economy, 108, $1-33$.

Allen, L., T.G. Bali, and Y. Tang (2012), "Does Systemic Risk in the Financial Sector Predict Future Economic Downturns?" Review of Financial Studies, 25, 3000-3036.

Andersen, T.G., T. Bollerslev, P.F. Christoffersen, and F.X. Diebold (2013), "Financial Risk Measurement for Financial Risk Management," In M. Harris, G. Constantinedes and R. Stulz (eds.), Handbook of the Economics of Finance, Volume 2, Part B, Elsevier, 11271220 .

Babus, A. (2013), "The Formation of Financial Networks," Manuscript, Imperial College London.

Barigozzi, M. and C. Brownlees (2013), "NETS: Network Estimation for Time Series," Manuscript, LSE and UPF.

Bianchi, D., M. Billio, R. Casarin, and M. Guidolin (2015), "Modeling Contagion and Systemic Risk," Manuscript, University Warwick, University of Venice and Bocconi University.

Billio, M., M. Getmansky, A.W. Lo, and L. Pelizzon (2012), "Econometric Measures of Connectedness and Systemic Risk in the Finance and Insurance Sectors," Journal of Financial Economics, 104, 535-559.

Bonaldi, P., A. Hortaçsu, and J. Kastl (2013), "An Empirical Analysis of Systemic Risk in the EURO-zone," Manuscript, University of Chicago.

Brownlees, C. and R.F. Engle (2015), "SRISK: A Conditional Capital Shortfall Index for Systemic Risk Measurement," Manuscript, Pompeu Fabra University and New York University.

Cifuentes, G., R. Ferrucci and H.S. Shin (2005), "Liquidity Risk and Contagion," Journal of the European Economic Association, 3, 556-566.

Diebold, F.X. and K. Yilmaz (2009), "Measuring Financial Asset Return and Volatility Spillovers, with Application to Global Equity Markets," Economic Journal, 119, 158171. 
Diebold, F.X. and K. Yilmaz (2012), "Better to Give than to Receive: Predictive Measurement of Volatility Spillovers (with discussion)," International Journal of Forecasting, 28, $57-66$.

Diebold, F.X. and K. Yilmaz (2014), "On the Network Topology of Variance Decompositions: Measuring the Connectedness of Financial Firms," Journal of Econometrics, 182, 119134 .

Easley, D. and J. Kleinberg (2010), Networks, Crowds and Markets, Cambridge University Press.

Garman, M. B. and M. J. Klass (1980), "On the Estimation of Security Price Volatilities From Historical Data," Journal of Business, 53, 67-78.

Giglio, S.W., B.T. Kelly, and S. Pruitt (2016), "Systemic Risk and the Macroeconomy: An Empirical Evaluation," Journal of Financial Economics, 119, 457-471.

Gorton, G. (2015), The Maze of Banking: History, Theory, Crisis, Oxford University Press.

Jackson, M.O. (2008), Social and Economic Networks, Princeton University Press.

Jacomy, M., S. Heymann, T. Venturini, and M. Bastian (2014), "ForceAtlas2, A Continuous Graph Layout Algorithm for Handy Network Visualization Designed for the Gephi Software," PLoS ONE, 9, www.plosone.org.

Koop, G., M.H. Pesaran, and S.M. Potter (1996), "Impulse Response Analysis in Nonlinear Multivariate Models," Journal of Econometrics, 74, 119-147.

Pesaran, H.H. and Y. Shin (1998), "Generalized Impulse Response Analysis in Linear Multivariate Models," Economics Letters, 58, 17-29.

Shleifer, A. and R.W. Vishny (1992), "Liquidity Values and Debt Capacity: A Market Equilibrium Approach," Journal of Finance, 47, 1343-1366.

Tibshirani, R. (1996), "Regression Shrinkage and Selection via the Lasso," Journal of the Royal Statistical Society, Series B (Methodological), 267-288.

Zou, H. and H. Zhang (2009), "On the Adaptive Elastic Net with a Diverging Number of Parameters," Annals of Statistics, 37, 1733. 